\title{
Ethnomedicinal Use, Phytochemistry, Pharmacology, and Toxicology of Salvia verbenaca L. : A Review
}

\author{
Aya Khouchlaa ${ }^{1, * \mathbb{D}}$, Abdeslam Et-Touys ${ }^{1 \mathbb{D}}$, Fatima Lakhdar ${ }^{2 \mathbb{D}}$, Fatima Ezzahra Laasri ${ }^{3}{ }^{\mathbb{D}}$, Amina \\ El Yahyaoui El Idrissi ${ }^{1}$, Fatna Zaakour ${ }^{4}$ (D) \\ 1 Laboratory of Human Pathologies Biology, Faculty of Science, Genomic Center of Human Pathologies, Faculty of \\ Medicine and Pharmacy, Mohammed V University in Rabat, Morocco; aya.khouchlaa@gmail.com (A.K.), \\ aettouys@gmail.com (A.E.-T.), elyahyaoui.amina@gmail.com (A.E.Y.E.I.); \\ 2 Department of Biology, Laboratory of Marine Biotechnology and Environment, Faculty of Sciences, Chouaib Doukkali \\ University, BP 20, El Jadida 24000, Morocco; fatimalakhdar24@ gmail.com (F.E.L.); \\ 3 Unit of Biology and Medical Research, National Center for Energy, Nuclear Science and Technology, Rabat, Morocco; \\ laasri.f92@gmail.com (F.E.L.); \\ 4 Laboratory of Sustainable Agriculture Management, Higher School of Technology Sidi Bennour, Chouaib Doukkali \\ University El Jadida, Morocco; zaakour-fatna@ hotmail.com (F.Z.); \\ * Correspondence: aya.khouchlaa@gmail.com (A.K.);
}

Scopus Author ID 57191631959

Received: 6.05.2021; Revised: 1.06.2021; Accepted: 5.06.2021; Published: 9.06.2021

Abstract: Salvia verbenaca L. is a Mediterranean medicinal plant used traditionally to treat several diseases such as burns, ocular wounds, contusion, stomach pain, eye diseases, dermal inflammation. This review highlighted previous reports, including the botanical, taxonomical, geographical distribution, traditional use, phytochemical, biological, and toxicological effects of S. verbenaca. The data were gathered from scientific databases PubMed, Scopus, Web of Science, Google Scholar, ScienceDirect, SpringerLink. The presented data on S. verbenaca were organized according to ethnomedicinal use, bioactive compounds, pharmacology, and toxicological investigation. Ethnobotanical studies reported that many folk medicines use S. verbenaca, especially against wounds, burns, and cicatrization. The phytochemical compounds in different parts of S. verbenaca belonged to different classes of chemical compounds, including terpenoids, flavonoids, phenolic acids, phenolic diterpenoids, and fatty acids. The extracts and essential oils from $S$. verbenaca have a wide variety of in vitro and in vivo pharmacological activities, i.e., antioxidant, antifungal, antidiabetic, antiinflammatory, antitumor, antihemolytic, antihypertensive, antileishmanial, and immunomodulatory activities. This research suggests that the biological activities of $S$. verbenaca prove its traditional uses. However, in-depth investigations are required, such as pharmacokinetic, pharmacodynamic, and toxicological experiments, to prove the efficacy and safety of $S$. verbenaca extracts and essential oils and their bioactive compounds.

Keywords: Salvia verbenaca; traditional use; phytochemistry compounds; pharmacological properties.

(C) 2021 by the authors. This article is an open-access article distributed under the terms and conditions of the Creative Commons Attribution (CC BY) license (https://creativecommons.org/licenses/by/4.0/).

\section{Introduction}

Salvia verbenaca L. belongs to the Lamiaceae family and the genus of Salvia. It is a perennial herbaceous plant [1] (10-30 cm in length) and is recognized by its strong pleasant smell and blue-lilac-colored flowers [2]. S. verbenaca is indigenous to the Mediterranean countries and the Canary Islands [3] and is distributed in the tropical region including Saudi Arabia [4], Central and South America, and Asia [5]. S. verbenaca know locally in Morocco 
and Algeria as "Khayata", in Italy as "Erba del malocchio", in French as "Fausse verveine", and in Spain as "Gallocresta" [6-8].

In traditional medicine, $S$. verbenaca is used against different illnesses, especially healing wounds in Morocco and Algeria [8-12]. It is also used to treat other diseases, including hypertension, constipation, muscle disorder, laryngitis, abscesses, contusion, stomach pain, eye diseases, dermal inflammatory, burns, ocular wounds [10, 13-18]. It is also used against respiratory diseases [19].

Many investigators reported the potential activity of $S$. verbenaca extracts and essential oils as antioxidant, antidiabetic, antibacterial, antifungal, antitumor, antihemolytic, antihypertensive, antileishmanial, and immunomodulatory activities [4, 20-23] (Figure 1). Furthermore, several studies investigated large variations according to geographical origin, diverse plant parts, genotype, and climate [2, 24-26], whereas there are scarcely those who reported the mechanistic investigations of these pharmacological effects. Phytochemical investigation of the extracts and essential oils from different parts of $S$. verbenaca showed the presence of numerous phytocompouds classes, including terpenoids, flavonoids, fatty acids, phenolic acids, phenolic diterpenoids, and carbonylic compounds [2,19,25].

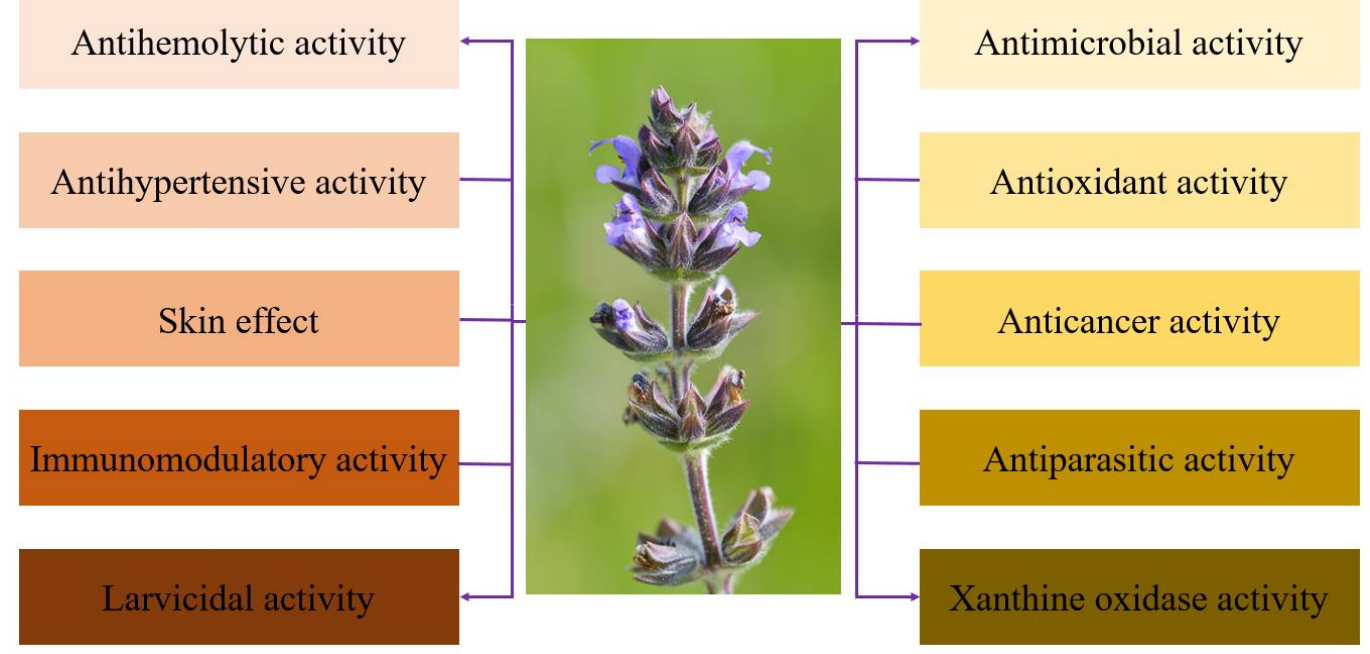

Figure 1. Pharmacological properties of S. verbenaca.

To the best of our knowledge, no review was published to critically summarized these results and suggested future clinical applications of this plant. Thus, this motivated us to write the current review, which highlighted $S$. verbenaca ethnomedicinal use, geographic distribution, taxonomy, phytochemical compounds, pharmacology activities, and toxicology effects.

\section{Materials and Methods}

The collected data of ethnomedicinal use, geographic distribution, taxonomy, phytochemical compounds, pharmacology activities, and toxicology effects of S. verbenaca was achieved from literature publication using various scientific search engines such as PubMed, Scopus, Web of Science, Google Scholar, ScienceDirect, SpringerLink, Scifnder, and Wiley Online to collected, analyzed, and summarized all published articles about this plant. In this research, several keywords were used such as "S. verbenaca", "ethnomedicinal of $S$. verbenaca", "S. verbenaca essentials oil", "antioxidant activity of $S$. verbenaca", "antidiabetic activity of $S$. verbenaca", "antibacterial activity of $S$. verbenaca", “antileishmanial activity of $S$. verbenaca”. All published articles mentioning $S$. verbenaca 
were cited in this bibliometric survey. To identify further relevant papers, reference lists of the retrieved papers were also examined. Dada was classified according to themes and organized into tables for their discussion. Concerning phytochemistry, chemical structures were drawn using ChemDraw Ultra 12.0 software.

\section{Results and Discussion}

\subsection{Botanical description.}

$S$. verbenaca is a perennial plant, $20-50 \mathrm{~cm}$ in height [27]. As depicted in figure 2, root is a woody rootstock. The leaves are simple, ovate to oblong-ovate $(2-10 \times 1.5-7 \mathrm{~cm})$, margin deeply sinuate to unevenly dentate, and upper cauline leaves sessile [28]. The petiole is 1.2-8 cm long. Nutlet fruits contain 1-4 seeds [29]. There are obovate, elliptic, rare spherical, dorsal, and ventral side's convex, rare rooflike on the ventral side, base with round fall in hilum (2.1$2.4 \times 1.6-1.9 \mathrm{~mm}$ ) [30]. The inflorescence is verticillasters, each of which contains 4-10 flowers of about $1 \mathrm{~cm}$ in length [28,29]. S. verbenaca flowering commences in mid-April and finishes towards the end of May [31]. The fruits mature about two weeks after the senescence of the flower. Each flower produces $0.6-1.5 \mu \mathrm{L}$ of nectar per day [31]. The calyx, \pm campanulate, is $5-12 \mathrm{~mm}$ in length with upper lip shortly 3-dentate. Corolla is 6-16 $\mathrm{mm}$ in length, lilac to purple, barely half as long as the calyx with a straight subfalcate upper lip, which is concave [28]. The plant cells are polyploid $(2 n=6 x=42,2 n=6 x=54,2 n=6 x=60,2 n=6 x=48,2 n=8 x=$ 64) [32].

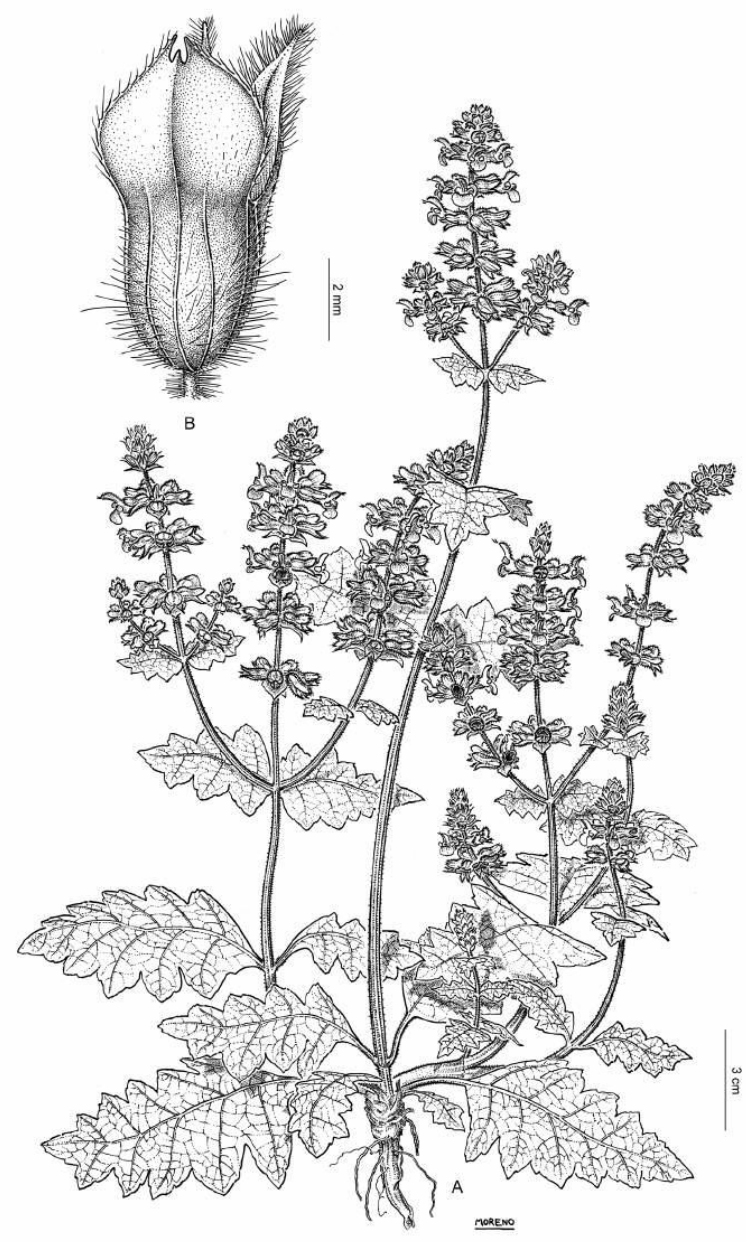

Figure 2. S. verbenaca. (A) general aspect; (B) flowers [33]. Illustration by Marcelo Moreno, taken from O’Leary \& Moroni (2016), courtesy: Instituto de Botánica Darwinion. 


\subsection{Taxonomy and geographic distribution.}

S. verbenaca belongs to the family Lamiaceae, which contains 900 species worldwide, of which about 26 indigenous species are found in southern Africa [3]. S. verbenaca is indigenous to the Mediterranean countries and has been reported all around the Mediterranean basin: From Morocco to the Canaries, from Algeria, Tunisia, Libya, Egypt, Cyprus, Turkey to Transcaucasia, from South and West of Europe to the North of Great Britain. It has been naturalized in America, southern Africa, New Zealand, and Australia [34, 35]. S. verbenaca is widely distributed within the altitude range of 1-2500 $\mathrm{m}$ in Argentina [33], and 1-900 $\mathrm{m}$ in Turkey except for East and Southeast Anatolia [36]. This species has been subservient to human activity, and its current distribution results from this action [37].

\subsection{Ethnobotanical use.}

In several folk medicines around the world, different parts of $S$. verbenaca have been reported by ethnobotanical surveys to treat several disorders (Table 1). S. verbenaca has an antispasmodic, ophthalmic, antiseptic, anti-rheumatic, antiseptic, antipyrotic, antisudoral, astringent effect as well as it has been reported for preventing stomach pain, cough, hypertension, insomnia, and aerophagia [6-12,15,16,38-42]. The traditional use of $S$. verbenaca depends on the country traditional medicine. Table 1 listed the applications of $S$. verbenaca in traditional global systems.

In Morocco, healing wounds, abscesses, and burns by $S$. verbenaca have been described as their famous prescription. The most used part of the plant is the leaves which are used as a cataplasm in the different regions, including Zaer (Western of Morocco), province of Settat (Morocco), and the province of Gharb-Chrarda-Beni Hssen (Northwest of Morocco) $[8,9,11,38,39]$. In addition to their healing effect, Nassiri et al. (2016) reported the use of $S$. verbenaca to treat digestive, respiratory, dermatological, and rheumatic illness in Aguelmous (Khenifra Province, Morocco) [43]. El Abbouyi et al. (2014) investigated the use of medicinal plants to treat different diseases in the El Jadida region and reported that the leaves of this plant were used as a decoction to treat abdominal colics, cold, and fever [40]. In the same year, Akdime et al. (2014) studied an ethnobotanical in the Ain Leuh region (Middel-Atlas of Morocco) and showed that the whole plant of $S$. verbenaca is used as antispasmodic, aerophagia, cough, preservative of butter, stomach pain, digestive, cough, and cicatrization [13]. In the Gharb region, surveys carried by Bouayyadi et al. (2015) showed that leaves of $S$. verbenaca are used in decoction to treat stomach pains [8]. Recently, Salhi and coworkers (2019) identified the use of the leaves and whole plant of $S$. verbenaca to heal skin burns by occidental population (Rabat, Morocco) by sprinkling it directly on burns or by application of its maceration with olive oil [44].

In Algeria, $S$. verbenaca was recorded as a medicinal plant against several pathologies, including healing wounds and abscesses $[10,12]$. It is also used as stomachic, tonic, vulnerary, disinfectant, antispasmodic, antisudoral, astringent (diarrhea), carminative by using a decoction or an infusion of aerial parts [16].

In European countries, various form of $S$. verbenaca has been reported to treat specific diseases. Tisane flower, fresh fruits, and aerial part infusion of $S$. verbenaca have been reported to treat hypertension [15], foreign bodies in the eye [7], and respiratory affections [41], respectively. In the Italian pharmacopeia, the leaves of this plant were used as a decoction to treat cystic and septic diseases $[6,42]$. 
From this study, many disorders have been reported using different parts of $S$. verbenaca depending on the geographical region using ethnobotanical surveys. This lasts is the first step to identify the plant used for each disorder. It informs about the part use, the mode of preparation, etc. However, the lack of plant information given by researchers in many surveys was repeatedly remarked. This is the case of several researchers who reported the use of $S$. verbenaca in folk medicine without mentioning the part use, the mode of preparation, and the traditional use [45-52]. Thus, conserving traditional herbal remedies by the local population requires standardization of fiche ethnobotanical surveys.

Table 1. Traditional use of $S$. verbenca.

\begin{tabular}{|c|c|c|c|}
\hline Used part & Mode of preparation & Traditional use & References \\
\hline Whole plant & Not reported & $\begin{array}{l}\text { Antispasmodic, aerophagia, cough, preservative of } \\
\text { butter, stomach pain, digestive, cough, cicatrization }\end{array}$ & {$[42]$} \\
\hline Aerial part & Decoction & Contusion, injury & {$[53]$} \\
\hline Seed & Not reported & Wounds eyes & [54] \\
\hline Leaf & Cataplasm & Wounds, drained abscesses, burns & {$[8,9]$} \\
\hline Leaf & Decoction & Stomach & {$[8]$} \\
\hline $\begin{array}{l}\text { Leaf, flowered aerial } \\
\text { part }\end{array}$ & Infusion & Respiratory affections & [41] \\
\hline Leaf & Not reported & Wound healing, abscess, laryngitis & {$[10]$} \\
\hline Leaf & Decoction, infusion & Abscesses, wounds & {$[14]$} \\
\hline Leaf & Cataplasm, decoction & Abdominal colics, cold, fever, healing & {$[14]$} \\
\hline Leaf & Not reported & Healing & [55] \\
\hline Flower & Tisane & Antipyertensive & {$[15]$} \\
\hline Leaf & Cataplasm & For curing cysts, pimples, wounds & {$[5,56]$} \\
\hline Fruit (nuts) & Fresh & Foreign bodies in the eye & [7] \\
\hline Aerial part, leaf & Infusion, decoction & $\begin{array}{l}\text { Stomachic, tonic, vulnerary, disinfectant, } \\
\text { antispasmodic, antisudoral, astringent, carminative }\end{array}$ & {$[16]$} \\
\hline Leaf & Not reported & Wounds, astringent, diuretic, antiseptic & [57] \\
\hline $\begin{array}{l}\text { Essential oil, powder } \\
\text { whole plant, leaves, } \\
\text { fruit, flower, root, rods }\end{array}$ & Cutaneous & Healing wounds & [39] \\
\hline Not reported & Not reported & Dermatological, digestives, respiratory, rheumatic & [43] \\
\hline Leaf & Ointment & Antipyrotic & {$[58]$} \\
\hline Leaf & Cataplasm & Wounds & [11] \\
\hline Leaf & Powder, maceration & Burns & \multirow[t]{2}{*}{ [44] } \\
\hline Whol plant & Powder & Burns & \\
\hline Leaf & Decoction & Antiseptic & [42] \\
\hline Leaf & Cataplasm & Healing wounds, anti-rheumatic & [38] \\
\hline Not reported & Not reported & $\begin{array}{l}\text { Indigestion, colds, hypertension, insomnia, anxiety, } \\
\text { ophthalmic antiseptic, hypertensive, dermal anti- } \\
\text { inflammatory washes, wax or oil anti-inflammatory } \\
\text { ointment, vulnerary and anti-inflammatory plaster, } \\
\text { snuff substitute, forage for rabbits }\end{array}$ & [17] \\
\hline Leaf & Powder & Wounds & [12] \\
\hline Leaf, seed & Not reported & $\begin{array}{l}\text { Constipation, against sweat, sedative, eye diseases, } \\
\text { dyspeptic, complaint }\end{array}$ & [18] \\
\hline Leaf & Not reported & Respiratory & [59] \\
\hline
\end{tabular}

\subsection{Phytochemistry.}

Several investigators reported the chemical composition of extracts and essential oils of $S$. verbenaca growing in different parts of the world [25,26,60-66]. Table 2 summarized the plant organs, the country of origin, the class of bioactive compounds, and the most abundant compounds of $S$. verbenaca extracts and essential oils. Terpenoids, flavonoids, fatty acids, phenolic acids, and carbonylic compounds were the classes of bioactive compounds identified. 


\subsubsection{Terpenoids.}

Various terpenoids were identified and characterized from S. verbenaca (Figure 3). In 1989, only one study identified the presence of terpenoids in roots. Sabri et al. (1989) isolated for the first time three terpenoids (Taxodione, horminone, and 613-hydroxy-7aacetoxyroyleanone) from the petroleum ether extract of the roots of $S$. verbenaca [67].

Ben Taarid et al. (2010a) carried out a phytochemical investigation of the leaves, fruits, and stems essential oils. The authors revealed the presence of 13-epi-manool, and manool in leaves, $\beta$-caryophyllene, and caryophyllene oxide in fruits and camphor, and viridiflorol in stems [60]. The chemical composition of essential oils of $S$. verbenaca leaves (Irano-Turanian) was determined by gas chromatography-mass spectrometry (GC-MS). $\delta$-Selinene was the main terpenoid, followed by germacrene $\mathrm{D}, \beta$-caryophyllene [61]. The same investigators reported that essential oils of $S$. verbenaca flowers (from Iran-Turanian) contained several terpenoids especially sabinene, and trans-sabinene hydrate [61]. In a recent study, Mannu and coworkers (2020) investigated the geographical variation of the chemical composition of essential oils extracted from Italian S. verbenaca [68]. They studied the chemical composition of leaves and flowers of S. verbenaca in six different geographical areas of Sardinia (Italy) and found that monoterpenes and sesquiterpenes were predominant regarding the altitude level. Germacrene D $(26.3 \%),(E)$ - $\beta$-caryophyllene (23.7\%), terpinolene (11.9\%), phytol (10.4\%), $\alpha$-humulene (4.6\%) were the main simple identified from the Asinara island area. Whereas germacrene D $(32.3 \%),(E)-\beta$-caryophyllene $(32.2 \%)$, and $\alpha$-humulene $(5.8 \%)$ were the main compounds identified from the Ala dei Sardi region. From this study, the authors showed that the essential oils profile significantly affected the site origin and the altitude for the four principal chemical groups identified.

Two studies investigated the phytochemical characterization of essential oils in seeds of $S$. verbenaca $[62,63]$. They both revealed that camphor and caryophyllene oxide were the main volatile compounds. Other terpenoids were also revealed, such as tricyclene, and octane identified in seeds of $S$. verbenaca collected from Tunisia, and 13-epi-manool, and $\alpha$-terpinyl acetate in seeds of $S$. verbenaca collected from Spain [62,63].

Al Howirine et al. (2002) identified sabinene, $\delta$-cadinene, $\alpha$-pinene, 4-terpeniol, and limonene as the main compounds of essential oils of $S$. verbenaca aerial part [26]. Four years later, the composition of the essential oil of the same part of $S$. verbenaca (Greece) using GCMS was analyzed by Pitarokili et al. (2006) [64]. They reported the presence of several terpenoids, including $\beta$-phellandrene, $\beta$-caryophyllene, and methyl ester of 6-octadecenoic acid as the main compounds, whereas viridiflorol, camphene, methyl eugenol, and $\beta$-caryophyllene were the main compounds identified in the same part of $S$. verbenaca essential oils (Tunisia) [70]. $\beta$-Phellandrene is the main component of the essential oils obtained from $S$. verbenaca aerial part (Italy). Russo and co-workers (2015) revealed the presence of hexadecanoic acid as the main component from the essential oils obtained from S. verbenaca aerial part (Italy) [27]. In the same year, verbenacine and salvinine have been isolated and identified by Ahmed et al. (2004) from the acetate extract of $S$. verbenaca aerial part harvested from Saudi Arabia [65]. Aissaoui and investigators (2014) analyzed the essential oils of S. verbenaca (Algeria) and found that it was very rich in sesquiterpenes [70]. It was found that 1,10-di-epi-cubenol, epi$\alpha$-cadinol, $\beta$-caryophyllene, bicyclogermacrene, $\gamma$-cadinene, cis muurola-4(14),5-diene were the most abundant compound. However, the main compounds of $S$. verbenaca essential oils from the same country (Algeria) were different in another research elaborated by Belloum and 
co-workers (2015) as they identified germacrene D, and $\alpha$-copaene [71], while Al Jaber and co-workers (2015) reported a dominance of linalool, and (Z)- $\beta$-ocimene in $S$. verbenaca essential oils from Jordan [72]. In Tunisia, Ben Farhat et al. (2019) investigated the composition of aerial part essential oils of $S$. verbenaca using gas chromatography (GC) and GC-MS [24]. They revealed the dominance of 1,8-cineole followed by $p$-cymene, viridiflorol, and $\beta$-Caryophyllene. Furthermore, these authors reported that monoterpene hydrocarbons were predominated at the flowering stage while oxygenated sesquiterpenes were dominant at the early fruiting stage. In a very recent study, cis-muurola-3,5 diene, and $\gamma$-amorphene have been identified as the main compounds in essential oils of $S$. verbenaca aerial part from Algeria [66]. The aerial part of $S$. verbenaca contained a diversity and difference of bioactive constituents, which could be assigned to the detection method, the distillation method, the collection time, the collect site, and the phenophase.<smiles>CC(C)C1=CC2=CC(=O)[C@@]3(C)C(C)(C)CCC[C@]3(C)C2=C(O)C1=O</smiles>

Taxodione

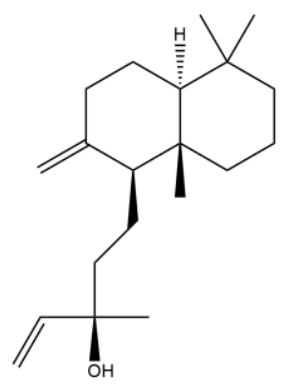

Manool<smiles>C=CCCC(/C=C\C(=C)CC/C=C\C)C(C)C</smiles><smiles>CC1=CCC(O)(C(C)C)CC1</smiles>

4-Terpineol

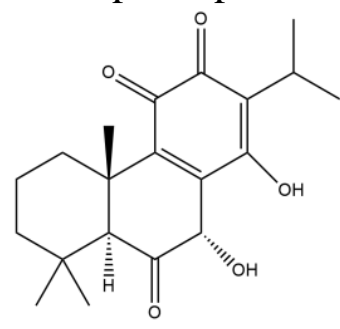

Horminone

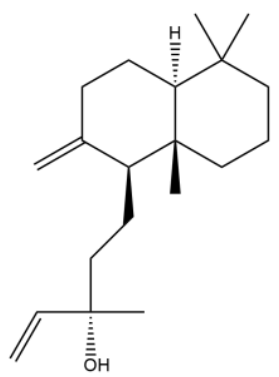

13-epi-manool

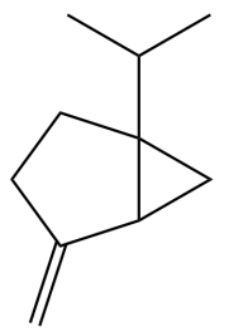

Sabinene<smiles>C=C(C)C1CC=C(C)CC1</smiles>

Limonene

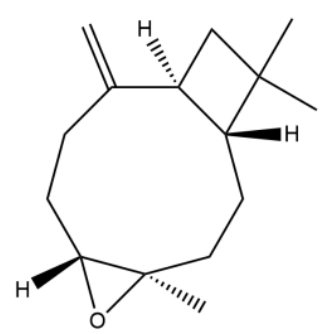

Caryophyllene oxide<smiles>CC1=C2C=C(C(C)C)CCC2(C)CCC1</smiles>

$\delta$-Selinene<smiles>CC1=C[C@]2(C)C(=C(C)CC1)CC[C@H]2C(C)C</smiles><smiles>C=C1C=CC(C(C)C(C)=O)CC1</smiles>

$\beta$-Phellandrene 


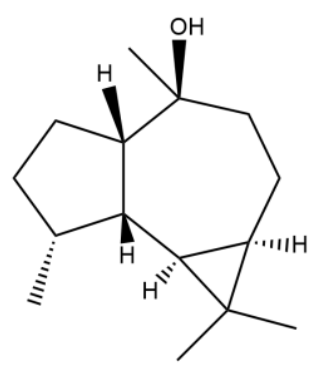

Viridiflorol

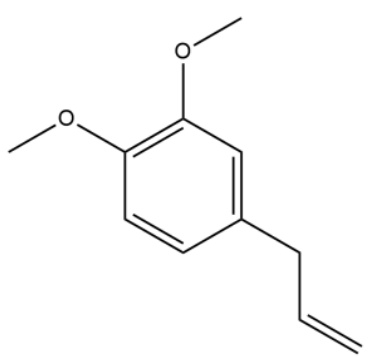

Methyl eugenol

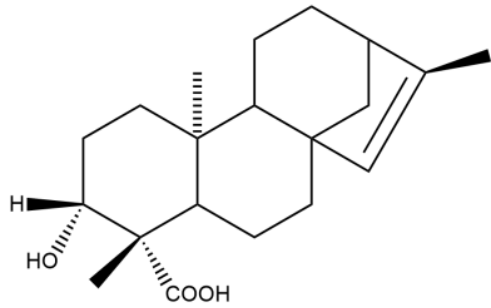

Verbenacine

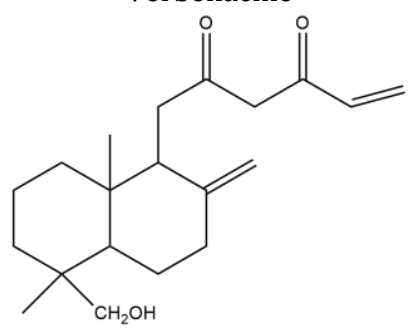

Salvinine

Linalool

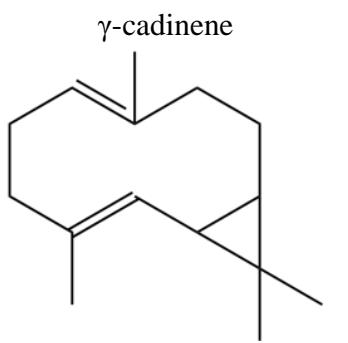

Bicyclogermacrene

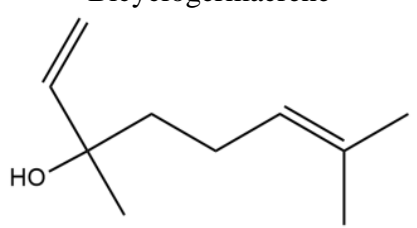

Figure 3. Chemical structure of terpenoids identified in $S$. verbenaca essential oils and extracts.

\subsubsection{Flavonoids.}

S. verbenaca was found to contain several flavonoids (Table 2, Figure 4). Camarasa et al. (1982) identified for the first time four flavonic aglycons (apigenin, luteolin, salvigenin, and 5-hydroxy-7,4'-dimethoxyflavone) from leaves of $S$. verbenaca harvested in Spain [73]. In 2005, Ahmed et al. (2005) isolated and identified three flavonoids (5-hydroxy-3,4',7trimethoxyflavone, retusin, verbenacoside) from $S$. verbenaca aerial part collected in Saudi Arabia [4]. Using HPLC, Ben Farhat et al. (2013) identified and quantified in 2013 various flavonoids in methanolic extract of $S$. verbenaca aerial part growing wild in ten Tunisian locations and collected at the flowering time in March and April 2008 [1]. Naringenin was the main compound identified in all stations, followed by cirsiliol in Rass Zebib, Tunis, Bou Arada, Sers, and Hancha location and by hesperidin in Bir Mroua, Beja, and Touiref station. The same tool was used to analyze the flavonoids compounds of $S$. verbenaca aerial part in three phonological stages using the same extract [25]. Naringenin and cirsiliol were the main flavonoid chemical family identified at the flowering stage compared with the early fruiting and late fruiting stages. From this study, the authors showed the significant effect of phenophase influenced in chemical compounds. Thus, studying chemical compounds at different phenophase periods is a way to valorize plant medicinals.<smiles>O=c1cc(-c2ccc(O)cc2)oc2cc(O)cc(O)c12</smiles>

Apigenin<smiles>O=c1cc(-c2ccc(O)c(O)c2)oc2cc(O)cc(O)c12</smiles>

Luteolin 
<smiles>COc1ccc(-c2cc(=O)c3c(O)c(OC)c(OC)cc3o2)cc1</smiles><smiles>COc1cc(O)c2c(=O)cc(-c3ccc(OC)c(OC)c3)oc2c1</smiles>

5-hydroxy-3,4',7-trimethoxyflavone

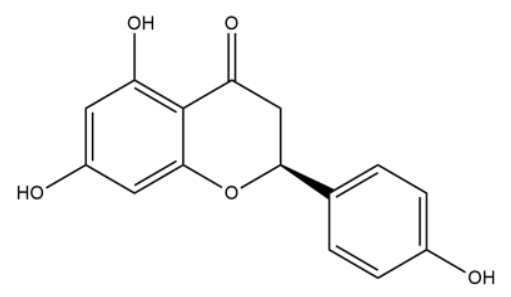

Naringenin

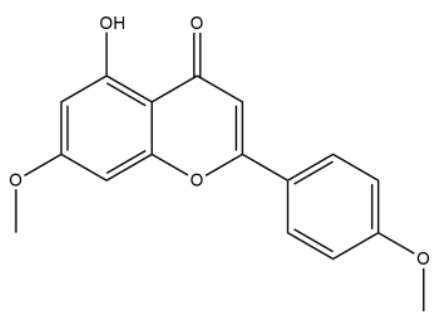

5-hydroxy-7,4'-dimethoxyflavone

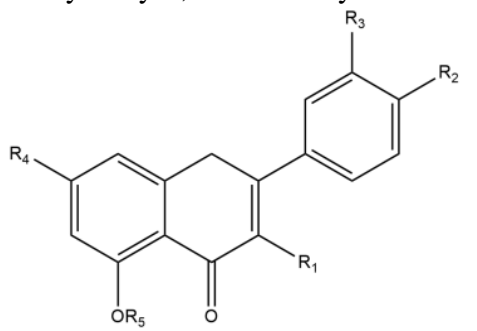

Retusin : $\mathrm{R}_{1}=\mathrm{R}_{2}=\mathrm{R}_{3}=\mathrm{R}_{4}=\mathrm{OMe}, \mathrm{R}_{5}=\mathrm{H}$

Verbenacoside : $\mathrm{R}_{1}=\mathrm{R}_{3}=\mathrm{R}_{4}=\mathrm{H}, \mathrm{R}_{2}=\mathrm{OH}, \mathrm{R}_{5}=\beta$-D-glucoside

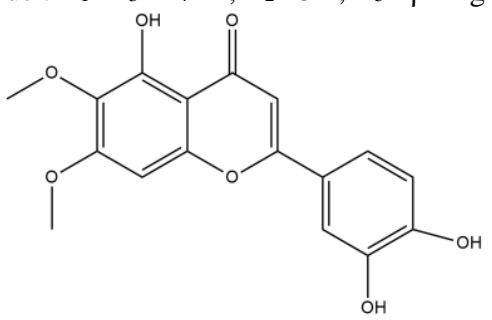

Cirsiliol

Figure 4. Chemical structure of flavonoids identified in S. verbenaca essential oils and extracts.

\subsubsection{Fatty acids.}

Certain fatty acids were identified from $S$. verbenaca essential oils using GC-MS and GC-FID (gas chromatography equipped with a flame ionization detector) [60,19,74]. Canzoneri and coworkers (2011) investigated the fatty acids composition of the essential oils obtained from S. verbenaca aerial part (Sicily, Italy) using GC-MS [19]. The authors found that essential oils were dominated by hexadecanoic acid followed by (Z)-9-octadecenoic acid and ethyl hexadecanoate. Ben Taarid and coworkers (2010b) evaluated the fatty acids composition of $S$. verbenaca, seed oil from Tunisia, extracted with chloroform/methanol mixture (2:1, v/v), in three stations (Sabelet Ben Ammar, Somâa, and Sers) [60]. According to the plant region, linolenic acid and linoleic acid were the dominant compounds $(45.89 \mathrm{mg} / \mathrm{g}$ and $27.39 \mathrm{mg} / \mathrm{g}$, respectively) with no significant differences in most fatty acid proportions. In 2015, Ben Farhat and investigators (2015) analyzed the composition of fatty acids of $S$. verbenaca seed (from Tunisia) in different habitats [74]. They showed that the main unsaturated fatty acids were linolenic acid and linoleic acid with a value of $45.02 \%$, and $23.36 \%$, respectively. In addition, these two compounds were the main fatty acids identified in all stations [74]. These results confirmed that the distribution of fatty acids did not depend on the region.

\subsubsection{Phenolic acids and phenolic diterpenoids.}

Chromatography analysis of phytochemical compounds of $S$. verbenaca extract revealed the presence of phenolic acids and phenolic diterpenoids. The work of Ben Farhat $e t$ al. (2013) identified the composition of methanolic extracts of $S$. verbenaca aerial part from Tunisia growing in ten different habitats [1]. They found that rosmarinic acid was the main 
phenolic acid of all analyzed samples (349.60 - $2560.37 \mu \mathrm{g} / \mathrm{g})$, followed by $p$-Hydroxybenzoic acid $(173.69-383.37 \mu \mathrm{g} / \mathrm{g})$ and caffeic acid $(30.79-231.37 \mu \mathrm{g} / \mathrm{g})$. Methyl carnosate was the major phenolic diterpenoids identified in all extracts. Two years later, Ben Farhat (2015) studied the chemical compounds of the same extract in three different phenological stages [25]. Rosmarinic acid was the main phenolic acid identified in all phonological stages (649.26 $544.51 \mu \mathrm{g} / \mathrm{g})$ followed by $p$-hydroxybenzoic acid $(83.62-47.27 \mu \mathrm{g} / \mathrm{g})$ and caffeic acid $(59.44$ $-42.36 \mu \mathrm{g} / \mathrm{g}$ ) in the early fruiting stage, and the late fruit stage. For phenolic diterpenoids, the major compounds were methyl carnosate and carnosic acid (821.45 - $919.82 \mu \mathrm{g} / \mathrm{g}$, and 110.22 - $199.60 \mu \mathrm{g} / \mathrm{g}$, respectively) (Figure 5, Table 2).<smiles>O=C(/C=C/c1ccc(O)c(O)c1)O[C@H](Cc1ccc(O)c(O)c1)C(=O)O</smiles>

Rosmarinic acid<smiles>O=C(O)/C=C/c1ccc(O)c(O)c1</smiles>

$p$-Hydroxybenzoic acid<smiles>CC(C)c1cc2c(c(O)c1O)[C@@]1(C(=O)O)CCCC(C)(C)[C@@]1(C)CC2</smiles>

Carnosic acid

Figure 5. Chemical structure of phenolic acid and phenolic diterpenoids identified in $S$. verbenaca extracts.

\subsubsection{Carbonylic compounds and hydrocarbons.}

The chemical composition of the essential oil of $S$. verbenaca from Italy was completely distinct from other essential oils by their composition of carbonylic compounds and hydrocarbons.<smiles>O=Cc1ccccc1</smiles><smiles>CCCCCCCCC</smiles>

Benzaldehyde Nonane<smiles>CC/C=C/C/C=C/C/C=C/CCCCCCCC=O</smiles>

9,12,15-Octadecatrienal

Figure 6. Chemical structure of carbonylic compounds and hydrocarbons identified in S. verbenaca.

Table 2. Phytochemistry of $S$. verbenaca.

\begin{tabular}{l|l|l|l|l} 
Used part & $\begin{array}{l}\text { Extracts/ essential } \\
\text { oils }\end{array}$ & $\begin{array}{l}\text { Compounds } \\
\text { groups }\end{array}$ & Main compounds & References \\
\hline $\begin{array}{l}\text { Aerial part } \\
\text { (Algeria) }\end{array}$ & Essential oils & Terpenoids & $\begin{array}{l}1,10 \text {-di-epi-cubenol }(20.9 \%) \\
\text { epi- } \alpha \text {-cadinol }(11.6 \%) \\
\beta-\text {-caryophyllene }(11.33 \%)\end{array}$ & {$[70]$} \\
& & $\begin{array}{l}\text { Bicyclogermacrene }(10.9 \%) \\
\gamma \text {-Cadinene }(7.9 \%) \\
\text { cis muurola-4(14),5-diene (7.8\%) }\end{array}$ &
\end{tabular}




\begin{tabular}{|c|c|c|c|c|}
\hline Used part & $\begin{array}{l}\text { Extracts/ essential } \\
\text { oils }\end{array}$ & $\begin{array}{l}\text { Compounds } \\
\text { groups }\end{array}$ & Main compounds & References \\
\hline $\begin{array}{l}\text { Aerial part } \\
\text { (Jordan) }\end{array}$ & Essential oils & Terpenoids & $\begin{array}{l}\text { Linalool }(61.32 \%) \\
(\mathrm{Z})-\beta \text {-Ocimene }(4.03 \%) \\
E \text { - } \beta \text {-Ocimene }(2.63 \%) \\
\text { Bicyclogermacrene }(5.94 \%) \\
\text { Spathulenol }(3.40 \%) \\
\beta \text {-Eudesmol }(3.66 \%)\end{array}$ & {$[71]$} \\
\hline $\begin{array}{l}\text { Leaves (Irano- } \\
\text { Turanian) }\end{array}$ & Essential oils & Terpenoids & $\begin{array}{l}\delta \text {-Selinene }(21.5 \%) \\
\text { Germacrene D }(19.8 \%) \\
\text { E-Caryophyllene }(11.4 \%) \\
\alpha \text {-Copaene }(9.6 \%) \\
\text { Sabinene }(9.0 \%) \\
\text { Z- } \beta \text {-Ocimene }(4.8 \%)\end{array}$ & {$[61]$} \\
\hline $\begin{array}{l}\text { Flowers (Irano- } \\
\text { Turanian) }\end{array}$ & Essential oils & Terpenoids & $\begin{array}{l}\text { Sabinene }(37.5 \%) \\
\text { trans-Sabinene hydrate }(20.0 \%) \\
\text { Z- } \beta \text {-ocimene }(9.9 \%) \\
E \text { - } \beta \text {-ocimene }(8.9 \%) \\
\alpha \text {-thujene }(4.6 \%)\end{array}$ & [61] \\
\hline $\begin{array}{l}\text { Aerial part } \\
\text { (Saudi Arabia) }\end{array}$ & Methanol extract & Flavonoids & $\begin{array}{l}\text { 5-hydroxy-3,4',7-trimethoxyflavone } \\
\text { Retusin } \\
\text { Verbenacoside }\end{array}$ & [4] \\
\hline $\begin{array}{l}\text { Aerial part } \\
\text { (Saudi Arabia) }\end{array}$ & Alcoholic extract & Terpenoids & $\begin{array}{l}\text { Verbenacine } \\
\text { Salvinine }\end{array}$ & {$[65]$} \\
\hline $\begin{array}{l}\text { Aerial parts } \\
\text { (Algeria) }\end{array}$ & Essential oils & Terpenoids & $\begin{array}{l}\text { Germacrene D }(20.5 \%) \\
\alpha \text {-Copaene }(10.4 \%) \\
\beta \text {-Caryophyllene }(3.8 \%) \\
\beta \text {-Phellandrene }(3.8 \%) \\
(\text { E)- } \beta \text {-Farnesene }(3.5 \%)\end{array}$ & [71] \\
\hline \multirow[t]{3}{*}{$\begin{array}{l}\text { Aerial parts } \\
\text { (Tunisia) }\end{array}$} & \multirow[t]{3}{*}{ Methanolic extract } & Phenolic acids & $\begin{array}{l}\text { Caffeic acid }(81.48 \mu \mathrm{g} / \mathrm{g}) \\
\text { Rosmarinic acid }(1065.78 \mu \mathrm{g} / \mathrm{g}) \\
p \text {-Hydroxybenzoic acid }(173.69 \mu \mathrm{g} / \mathrm{g})\end{array}$ & \multirow[t]{3}{*}[1]{} \\
\hline & & $\begin{array}{l}\text { Phenolic } \\
\text { diterpenes }\end{array}$ & $\begin{array}{l}\text { Carnosic acid }(65.83 \mu \mathrm{g} / \mathrm{g}) \\
\text { methyl carnosate }(286.37 \mu \mathrm{g} / \mathrm{g})\end{array}$ & \\
\hline & & Flavonoids & $\begin{array}{l}\text { Hesperidin }(39.37 \mu \mathrm{g} / \mathrm{g}) \\
\text { Naringenin }(472.03 \mu \mathrm{g} / \mathrm{g}) \\
\text { Cirsiliol }(75.44 \mu \mathrm{g} / \mathrm{g})\end{array}$ & \\
\hline Seed (Tunisia) & Oil extract & Fatty acids & $\begin{array}{l}\text { Oleic acid }(16.45 \%) \\
\text { Linoleic acid }(23.36 \%) \\
\text { Linolenic acid }(45.02 \%)\end{array}$ & [74] \\
\hline \multirow[t]{3}{*}{$\begin{array}{l}\text { Aerial parts } \\
\text { (Tunisia) }\end{array}$} & \multirow[t]{3}{*}{ Methanolic extract } & Phenolic acids & $\begin{array}{l}\text { Rosmarinic acid }(544.51 \mu \mathrm{g} / \mathrm{g}) \\
\text { Caffeic acid }(68.75 \mu \mathrm{g} / \mathrm{g}) \\
p \text {-Hydroxybenzoic acid }(67.02 \mu \mathrm{g} / \mathrm{g}) \\
\text { Ferulic acid }(32.46 \mu \mathrm{g} / \mathrm{g})\end{array}$ & \multirow[t]{3}{*}[25]{} \\
\hline & & $\begin{array}{l}\text { Phenolic } \\
\text { diterpenes }\end{array}$ & $\begin{array}{l}\text { Methyl carnosate }(919.82 \mu \mathrm{g} / \mathrm{g}) \\
\text { Carnosic acid }(110.22 \mu \mathrm{g} / \mathrm{g})\end{array}$ & \\
\hline & & Flavonoids & $\begin{array}{l}\text { Naringenin }(241.50 \mu \mathrm{g} / \mathrm{g}) \\
\text { Cirsiliol }(71.57 \mu \mathrm{g} / \mathrm{g}) \\
\text { Cirsilineol }(24.65 \mu \mathrm{g} / \mathrm{g})\end{array}$ & \\
\hline $\begin{array}{l}\text { Aerial parts } \\
\text { (Tunisia) }\end{array}$ & Essential oil & Terpenoids & $\begin{array}{l}1,8 \text {-Cineole }(9.7 \%) \\
p \text {-Cymene }(8.4 \%) \\
\text { Viridiflorol }(7.3 \%) \\
\beta \text {-Caryophyllene }(5.3 \%) \\
\text { epi-13-Manool }(4.7 \%)\end{array}$ & {$[24]$} \\
\hline Seed (Spain) & Essential oil & Terpenoids & $\begin{array}{l}\text { Camphor }(38.94 \%) \\
\text { Caryophyllene oxide }(7.28 \%) \\
\text { 13-epi-Manool }(5.61 \%) \\
\alpha \text {-Terpinyl acetate }(4.77 \%) \\
\end{array}$ & [63] \\
\hline Leaf (Tunisia) & Essential oil & Terpenoids & $\begin{array}{l}\text { epi-13-manool }(13.7 \%) \\
\text { Manool }(11.0 \%) \\
\text { Caryophyllene oxide }(3.9 \%)\end{array}$ & [60] \\
\hline
\end{tabular}




\begin{tabular}{|c|c|c|c|c|}
\hline Used part & $\begin{array}{l}\text { Extracts/ essential } \\
\text { oils }\end{array}$ & $\begin{array}{l}\text { Compounds } \\
\text { groups }\end{array}$ & Main compounds & References \\
\hline & & & Camphor (3.9\%) & \\
\hline Fruit (Tunisia) & Essential oil & Terpenoids & $\begin{array}{l}\beta \text {-Caryophyllene }(23.1 \%) \\
\text { Caryophyllene oxide }(15.9 \%) \\
\text { Camphene }(6.5 \%) \\
\alpha \text {-Humulene }(5.6 \%) \\
\text { Viridiflorol }(4.3 \%)\end{array}$ & \\
\hline Stem (Tunisia) & Essential oil & Terpenoids & $\begin{array}{l}\text { Camphor }(10.9 \%) \\
\text { Viridiflorol }(10.3 \%) \\
\text { Terpinolene }(6.6 \%) \\
\text { Methyl eugenol }(6.1 \%) \\
\alpha-\text { Pinene }(5.9 \%) \\
\end{array}$ & \\
\hline \multirow[t]{2}{*}{ Seed (Tunisia) } & Essential oil & Terpenoids & $\begin{array}{l}\text { Camphor }(33.83 \%) \\
\text { Caryophyllene oxide }(10.11 \%) \\
\text { Tricyclène }(5.54 \%) \\
\text { Octane }(4.78 \%)\end{array}$ & \multirow[t]{2}{*}[62]{} \\
\hline & & Fatty acids & $\begin{array}{l}\text { Linolenic acid }(45.89 \mathrm{mg} / \mathrm{g}) \\
\text { Linoleic acid }(27.39 \mathrm{mg} / \mathrm{g}) \\
\text { Oleic acid }(14.67 \mathrm{mg} / \mathrm{g})\end{array}$ & \\
\hline $\begin{array}{l}\text { Aerial part } \\
\text { (Tunisia) }\end{array}$ & Essential oil & Terpenoids & $\begin{array}{l}\text { Viridiflorol }(21.8 \%) \\
\text { Camphene }(17.6 \%) \\
\text { Methyl eugenol }(9.4 \%) \\
\beta \text {-caryophyllene }(7.1 \%)\end{array}$ & [69] \\
\hline \multirow[t]{4}{*}{$\begin{array}{l}\text { Aerial part } \\
\text { (Italy) }\end{array}$} & \multirow[t]{4}{*}{ Essential oil } & Hydrocarbons & $\begin{array}{l}\text { Nonane }(1.2 \%) \\
\text { Tricosane }(0.9 \%)\end{array}$ & \multirow[t]{4}{*}[19]{} \\
\hline & & $\begin{array}{l}\text { Carbonylic } \\
\text { compounds }\end{array}$ & $\begin{array}{l}\text { Benzaldehyde }(7.3 \%) \\
9,12,15 \text {-Octadecatrienal }(2.9 \%) \\
(E) \text { - } \beta \text {-Ionone }(1.9 \%) \\
(E) \text {-2-Hexenal }(1.5 \%) \\
\text { Phenyl acetaldehyde }(1.5 \%)\end{array}$ & \\
\hline & & Terpenoids & $\begin{array}{l}\beta \text {-Phellandrene }(5.9 \%) \\
\text { Limonene }(2.0 \%) \\
\text { Caryophyllene oxide }(1.9 \%) \\
(E) \text {-Caryophyllene }(1.2 \%) \\
\text { Linalool }(0.7 \%)\end{array}$ & \\
\hline & & Fatty acids & $\begin{array}{l}\text { Hexadecanoic acid }(23.1 \%) \\
(Z)-9-\text {-Octadecenoic acid }(11.1 \%) \\
\text { Ethyl hexadecanoate }(2.6 \%)\end{array}$ & \\
\hline $\begin{array}{l}\text { Aerial part } \\
\text { (Saudi Arabia) }\end{array}$ & Essential oil & Terpenoids & $\begin{array}{l}\text { Sabinene }(16.0 \%) \\
\delta \text {-cadinene }(7.9 \%) \\
\text { alpha-Pinene }(7.3 \%) \\
\text { 4-Terpeniol }(7.4 \%) \\
\text { Limonene }(6.7 \%)\end{array}$ & [26] \\
\hline $\begin{array}{l}\text { Aerial part } \\
\text { (Algeria) }\end{array}$ & Essential oil & Terpenoids & $\begin{array}{l}\text { cis-Muurola-3,5 diene (14.6\%) } \\
\gamma \text {-amorphene }(10.5 \%) \\
\text { Bicyclogermacrene }(6.8 \%) \\
\gamma \text {-cadinene }(4.8 \%) \\
2,3 \text {-dehydro-1,4-cineol }(3.7 \%)\end{array}$ & [66] \\
\hline $\begin{array}{l}\text { Aerial part } \\
\text { (Greece) }\end{array}$ & Essential oil & Terpenoids & $\begin{array}{l}\beta \text {-Phellandrene }(30.3 \%) \\
(E) \text {-Caryophyllene }(16.1 \%) \\
\text { Methyl ester of 6-octadecenoic acid } \\
(15.0 \%)\end{array}$ & {$[64]$} \\
\hline $\begin{array}{l}\text { Aerial part } \\
\text { (Italy) }\end{array}$ & Essential oil & Terpenoids & $\begin{array}{l}\text { Hexadecanoic acid }(23.1 \%) \\
\text { (Z)-9-Octadecenoic acid }(11.1 \%) \\
\text { Benzaldehyde }(7.3 \%)\end{array}$ & [27] \\
\hline $\begin{array}{l}\text { Flowers, leaves } \\
\text { (Italy) }\end{array}$ & Essential oil & Terpenoids & $\begin{array}{l}\text { Terpinolene }(11.9 \%) \\
(\text { E)- } \beta \text {-caryophyllene }(23.7 \%) \\
\text { Germacrene D }(26.3 \%) \\
\text { Phytol }(10.4 \%) \\
\alpha \text {-humulene }(4.6 \%)\end{array}$ & [68] \\
\hline
\end{tabular}


Benzaldehyde and 9,12,15-Octadecatrienal were the main carbonylic compounds identified in $S$. verbenaca essential oils $(7.3 \%$ and $2.9 \%)$, while nonane was the main hydrocarbons with the value of 1.2\% [19] (Figure 6, Table 2).

\subsection{Pharmacological investigation.}

\subsubsection{Antibacterial activity.}

Several studies reported the antibacterial efficacy of different extracts and essential oils from different plant parts of S. verbenaca [21,26,19,75-79]. As reported, the antibacterial activity of the essential oils and extracts from different parts of $S$. verbenaca, type of extract, type of antibacterial assay, tested strains, and mains results are summarized in Table 3.

Al Howirine (2002) studied the antibacterial effect of essential oils obtained from the aerial parts of this plant from Saudi Arabia against five strains [26]. They showed a similar antibacterial effect of tested oil against Bacillus subtilis (MIC $=2.0 \mathrm{mg} / \mathrm{mL}$ ), Staphylococcus aureus $(\mathrm{MIC}=2.0 \mathrm{mg} / \mathrm{mL}$ ), and Mycobacterium smegmatis $(\mathrm{MIC}=3.0 \mathrm{mg} / \mathrm{mL}$ ) while no effect has been reported for Escherichia coli, and Pseudomonas aeruginosa. Canzoneri et al. (2011) also investigated the antibacterial activity of $S$. verbenaca essential oils from aerial parts (Sicily, Italia) using the dilution method against Gram-negative and Gram-positive bacteria [19]. The authors reported that essential oils were not active against Gram- bacteria (MIC > $100 \mu \mathrm{g} / \mathrm{mL}$ ), while it exhibited a good antimicrobial effect against B. subtilis, and Staphylococcus epidermidis ( $\mathrm{MIC}=50 \mu \mathrm{g} / \mathrm{mL}$, for both strains).

Researchers reported the effect of organic extract of $S$. verbenaca against Gram- and Gram+ bacteria. The antibacterial activity of leaves methanolic extract of $S$. verbenaca from Tunisia was tested using the agar diffusion method [75]. According to this study, the MICs varied from 500 to $1000 \mu \mathrm{g} / \mathrm{mL}$, and the extracts seemed to be selective. Leaves methanolic extracts exhibited the same potent antibacterial against S. epidermidis, Staphylococcus cohnii, Corynebacterium gr. C, Corynebacterium gr. D2, Micrococcus sedentarius, and Corynebacterium xerosis, while less activity was obtained for Micrococcus luteus, Staphylococcus intermedius, Pseudomonas cepacia, and P. aeruginosa (MIC > $1000 \mu \mathrm{g} / \mathrm{mL}$ ). In 2007, Kamatou et al. (2007) evaluated in vitro the antibacterial effects of methanol:chloroform of $S$. verbenaca aerial parts using microdilution assay against $E$. coli, $K$. pneumonia, B. cereus, and $S$. aureus [76]. From this study, the authors demonstrated that $K$. pneumonia and B. cereus (MIC $=2 \mathrm{mg} / \mathrm{mL}$ ) were the most sensitive bacteria in $1: 1$ dilution. In another study, Sarac et Ugur (2007) reported the growth inhibitory effect of ethanol extract of this plant (Mugla, Turkey) on various pathogenic bacteria with inhibition zones ranged between 9-11 mm [77].

The antibacterial activity of ethyl acetate extract of $S$. verbenaca from the southern part of Al Karak governorate (Jordan) and Bordj-Bou-Arerridj region (Algeria) was tested using agar and disc diffusion methods [21,78]. Al-Zereini (2017) evaluated the effect of ethyl acetate extract of $S$. verbenaca leaves (Jordan) [78]. At $100 \mathrm{mg} / \mathrm{mL}$, the extract exhibited low inhibitory zones of $9.3 \pm 0.6 \mathrm{~mm}$ and $7.1 \pm 1.2 \mathrm{~mm}$ for Bacillus brevis, and B. subtilis, respectively. The same extract of $S$. verbenaca from aerial part growth in Algeria was investigated against eight microorganisms in the next year. The authors studied the effect of two different concentrations $(100 \mathrm{mg} / \mathrm{ml}$ and $200 \mathrm{mg} / \mathrm{ml})$ and indicated a proportional effect of S. verbenaca ethyl acetate extract concentration. At $200 \mathrm{mg} / \mathrm{mL}$, the inhibitory zone varied 
between 13 and $16 \mathrm{~mm}$, with a large inhibitory zone was reported against $S$. aureus $(16 \mathrm{~mm})$ [21].

Kabouche and Kabouche (2008) investigated the antibacterial activity of root acetone extract at $128 \mathrm{mg} / \mathrm{mL}$ against several strains [79]. The results indicated that B. subtilis $(28 \mathrm{~mm}$, $\mathrm{MIC}=4 \mu \mathrm{g} / \mathrm{mL})$, S. aureus $(26 \mathrm{~mm}, \mathrm{MIC}=16 \mu \mathrm{g} / \mathrm{mL})$, and Streptoccocus hemolytic $(22 \mathrm{~mm}$, $\mathrm{MIC}=6 \mu \mathrm{g} / \mathrm{mL}$ ) were extremely sensitive to the concentration of $128 \mathrm{mg} / \mathrm{mL}$ while a week antibacterial effect was reported for E. coli, K. pneumonia, P. mirabilis, and S. hemolytic.

All these researches reported that $S$. verbenaca presented an important antibacterial effect with a variation of the results depend on different factors including extract used, localization of plant, period of collect, used part, extraction methods, the experimental used as well as bioactive compounds present in the plant [80]. However, the mechanism by with extracts and essential oils exhibited their effect was not fully understood. Indeed, different researchers reported that bioactive molecules such as flavonoids have the ability to form complexes with extracellular and solubles protein as well as the cell wall [75]. Naringenin, a flavonoid belonging to the flavanones subclass, showed an important antibacterial activity by decreasing biofilm formation and decreasing fatty acid secretion [81]. Moreover, modifying cell morphology and gene expression, increasing cell permeability, and inhibiting the quorumsensing system are also mechanisms of pathways by which molecules exert their effects on bacteria $[20,82,83]$. Furthermore, the synergistic effects of the major and the minor phenolic compounds should be taken into consideration

Table 3. Antibacterial activity of $S$. verbenaca.

\begin{tabular}{|c|c|c|c|c|c|}
\hline $\begin{array}{l}\text { Part } \\
\text { used }\end{array}$ & $\begin{array}{l}\text { Extract } \\
\text { tested }\end{array}$ & Method used & Tested strains & Keys results & References \\
\hline \multirow[t]{2}{*}{ Leaves } & \multirow{2}{*}{$\begin{array}{l}\text { Ethyl acetate } \\
(100 \mathrm{mg} / \mathrm{ml})\end{array}$} & \multirow{2}{*}{$\begin{array}{l}\text { Agar diffusion } \\
\text { method }\end{array}$} & Bacillus brevis ATCC 9999 & $\Phi=9.3 \pm 0.6 \mathrm{~mm}$ & \multirow[t]{2}{*}[78]{} \\
\hline & & & Bacillus subtilis ATCC 6633 & $\Phi=7.1 \pm 1.2 \mathrm{~mm}$ & \\
\hline \multirow{8}{*}{$\begin{array}{l}\text { Aerial } \\
\text { part }\end{array}$} & \multirow{8}{*}{$\begin{array}{l}\text { Ethyl acetate } \\
(100 \mathrm{mg} / \mathrm{ml})\end{array}$} & \multirow{8}{*}{$\begin{array}{l}\text { Disc diffusion } \\
\text { method }\end{array}$} & Escherichia coli ATCC 25922 & $\Phi=11 \mathrm{~mm}$ & \multirow[t]{8}{*}[21]{} \\
\hline & & & $\begin{array}{l}\text { Pseudomonas aeruginosa ATCC } \\
27853\end{array}$ & $\Phi=12 \mathrm{~mm}$ & \\
\hline & & & $\begin{array}{l}\text { Staphylococcus aureus ATCC } \\
52952\end{array}$ & $\Phi=12 \mathrm{~mm}$ & \\
\hline & & & Bacillus cereus ATCC 10876 & $\Phi=13 \mathrm{~mm}$ & \\
\hline & & & P. mirabilis ATCC 35659 & $\Phi=13 \mathrm{~mm}$ & \\
\hline & & & $\begin{array}{l}\text { Enterococcus faecalis ATCC } \\
49452\end{array}$ & $\Phi=12 \mathrm{~mm}$ & \\
\hline & & & Citrobacter freundii ATCC 8090 & $\Phi=12 \mathrm{~mm}$ & \\
\hline & & & $\begin{array}{l}\text { Acenetobacter baumanii ATCC } \\
19306\end{array}$ & $\Phi=10 \mathrm{~mm}$ & \\
\hline \multirow{4}{*}{$\begin{array}{l}\text { Aerial } \\
\text { parts }\end{array}$} & \multirow{4}{*}{$\begin{array}{l}\text { Essential oil } \\
\text { - }\end{array}$} & \multirow{4}{*}{$\begin{array}{l}\text { Broth dilution } \\
\text { method }\end{array}$} & Staphylococcus aureus & $\mathrm{MIC}=100 \mu \mathrm{g} / \mathrm{mL}$ & \multirow[t]{4}{*}{ [19] } \\
\hline & & & Streptococcus faecalis & $\mathrm{MIC}=100 \mu \mathrm{g} / \mathrm{mL}$ & \\
\hline & & & Bacillus subtilis & $\mathrm{MIC}=50 \mu \mathrm{g} / \mathrm{mL}$ & \\
\hline & & & Staphylococcus epidermidis & $\mathrm{MIC}=50 \mu \mathrm{g} / \mathrm{mL}$ & \\
\hline \multirow{3}{*}{$\begin{array}{l}\text { Aerial } \\
\text { parts }\end{array}$} & \multirow{3}{*}{$\begin{array}{l}\text { Essential oil } \\
\text { - }\end{array}$} & \multirow[t]{3}{*}{-} & Bacillus subtilis & $\mathrm{MIC}=2.0 \mathrm{mg} / \mathrm{mL}$ & \multirow[t]{3}{*}{ [26] } \\
\hline & & & Staphylococcus aureus & $\mathrm{MIC}=2.0 \mathrm{mg} / \mathrm{mL}$ & \\
\hline & & & Mycobacterium smegmatis & $\mathrm{MIC}=3.0 \mathrm{mg} / \mathrm{mL}$ & \\
\hline \multirow[t]{5}{*}{ Root } & \multirow{5}{*}{$\begin{array}{l}\text { Acetone } \\
\text { extract (128 } \\
\mathrm{mg} / \mathrm{ml})\end{array}$} & \multirow[t]{5}{*}{-} & Bacillus subtilis & $\begin{array}{l}\Phi=28 \mathrm{~mm} \\
\mathrm{MIC}=4 \mu \mathrm{g} / \mathrm{mL}\end{array}$ & \multirow[t]{5}{*}{ [79] } \\
\hline & & & Escherichia coli & $\begin{array}{l}\Phi=14 \mathrm{~mm} \\
\mathrm{MIC}=128 \mu \mathrm{g} / \mathrm{mL}\end{array}$ & \\
\hline & & & Klebsiella pneumonia & $\begin{array}{l}\Phi=12 \mathrm{~mm} \\
\mathrm{MIC}>128 \mu \mathrm{g} / \mathrm{mL}\end{array}$ & \\
\hline & & & Proteus mirabilis & $\begin{array}{l}\Phi=8 \mathrm{~mm} \\
\mathrm{MIC}>128 \mu \mathrm{g} / \mathrm{mL}\end{array}$ & \\
\hline & & & Staphylococcus aureus & $\Phi=26 \mathrm{~mm}$ & \\
\hline
\end{tabular}




\begin{tabular}{|c|c|c|c|c|c|}
\hline $\begin{array}{l}\text { Part } \\
\text { used }\end{array}$ & $\begin{array}{l}\text { Extract } \\
\text { tested }\end{array}$ & Method used & Tested strains & Keys results & References \\
\hline & & & & $\mathrm{MIC}=16 \mu \mathrm{g} / \mathrm{mL}$ & \\
\hline & & & Streptoccocus hemolitic & $\begin{array}{l}\Phi=22 \mathrm{~mm} \\
\mathrm{MIC}=6 \mu \mathrm{g} / \mathrm{mL}\end{array}$ & \\
\hline \multirow{4}{*}{$\begin{array}{l}\text { Aerial } \\
\text { parts }\end{array}$} & \multirow{4}{*}{$\begin{array}{l}\text { Methanol: } \\
\text { chloroform } \\
(1: 1) \text { extracts }\end{array}$} & \multirow[t]{4}{*}{ Micro-dilution } & E. coli ATCC 8739 & $\mathrm{MIC}=8 \mathrm{mg} / \mathrm{mL}$ & \multirow[t]{4}{*}{ [76] } \\
\hline & & & K. pneumoniae NCTC 9633 & $\mathrm{MIC}=2 \mathrm{mg} / \mathrm{mL}$ & \\
\hline & & & B. cereus ATCC 11778 & $\mathrm{MIC}=2 \mathrm{mg} / \mathrm{mL}$ & \\
\hline & & & S. aureus ATCC 25923 & $\mathrm{MIC}=3 \mathrm{mg} / \mathrm{mL}$ & \\
\hline \multirow[t]{5}{*}{-} & \multirow{5}{*}{$\begin{array}{l}\text { Ethanol } \\
\text { extract }\end{array}$} & \multirow{5}{*}{$\begin{array}{l}\text { Disk diffusion } \\
\text { method }\end{array}$} & B. subtilis ATCC 6633 & $\Phi=9 \mathrm{~mm}$ & \multirow[t]{5}{*}{ [77] } \\
\hline & & & S. aureus ATCC 25923 & $\Phi=11 \mathrm{~mm}$ & \\
\hline & & & S. aureus MU 38 & $\Phi=9 \mathrm{~mm}$ & \\
\hline & & & S. aureus MU 44 & $\Phi=10 \mathrm{~mm}$ & \\
\hline & & & S. epidermidis MU 30 & $\Phi=9 \mathrm{~mm}$ & \\
\hline \multirow[t]{15}{*}{ Leaves } & \multirow[t]{15}{*}{$\begin{array}{l}\text { Methanolic } \\
\text { extract }\end{array}$} & \multirow[t]{15}{*}{$\begin{array}{l}\text { Agar diffusion } \\
\text { method }\end{array}$} & $\begin{array}{l}\text { Staphylococcus epidermidis } \\
\text { (L1S2) }\end{array}$ & $\mathrm{MIC}=500 \mu \mathrm{g} / \mathrm{mL}$ & \multirow[t]{15}{*}[75]{} \\
\hline & & & Staphylococcus cohnii (L6S3) & $\mathrm{MIC}=500 \mu \mathrm{g} / \mathrm{mL}$ & \\
\hline & & & Corynebacterium gr. B (L16C3) & $\mathrm{MIC}>1000 \mu \mathrm{g} / \mathrm{mL}$ & \\
\hline & & & Corynebacterium gr. C (L3C3) & $\mathrm{MIC}=500 \mu \mathrm{g} / \mathrm{mL}$ & \\
\hline & & & $\begin{array}{l}\text { Corynebacterium gr. D2 } \\
\text { (L19C1) }\end{array}$ & $\mathrm{MIC}=500 \mu \mathrm{g} / \mathrm{mL}$ & \\
\hline & & & Micrococcus sedentarius (L7B5) & $\mathrm{MIC}=500 \mu \mathrm{g} / \mathrm{mL}$ & \\
\hline & & & Acinetobacter sp. (LH5DC1) & $\mathrm{MIC}=700 \mu \mathrm{g} / \mathrm{mL}$ & \\
\hline & & & Moraxella sp. (LH7SV1) & $\mathrm{MIC}>1000 \mu \mathrm{g} / \mathrm{mL}$ & \\
\hline & & & Alcaligenes sp. (LH4TV1) & $\mathrm{MIC}>1000 \mu \mathrm{g} / \mathrm{mL}$ & \\
\hline & & & Staphylococcus xylosus (IP8166) & $\mathrm{MIC}>1000 \mu \mathrm{g} / \mathrm{mL}$ & \\
\hline & & & $\begin{array}{l}\text { Corynebacterium xerosis } \\
\text { (IP5216) }\end{array}$ & $\mathrm{MIC}=500 \mu \mathrm{g} / \mathrm{mL}$ & \\
\hline & & & Micrococcus luteus (L1C5) & $\mathrm{MIC}>1000 \mu \mathrm{g} / \mathrm{mL}$ & \\
\hline & & & $\begin{array}{l}\text { Staphylococcus intermedius } \\
\text { (IP8160) }\end{array}$ & $\mathrm{MIC}>1000 \mu \mathrm{g} / \mathrm{mL}$ & \\
\hline & & & Pseudomonas cepacia (V6108) & $\mathrm{MIC}>1000 \mu \mathrm{g} / \mathrm{mL}$ & \\
\hline & & & $\begin{array}{l}\text { Pseudomonas aeruginosa } \\
\text { (V5791) }\end{array}$ & $\mathrm{MIC}>1000 \mu \mathrm{g} / \mathrm{mL}$ & \\
\hline
\end{tabular}

\subsubsection{Antifungal activity.}

The antifungal activity of $S$. verbenaca essential oils and the methanolic extract was elaborated by two studies [26,75] (Table 4). The essential oil extracted from aerial parts of $S$. verbenaca, rich in sabinene and $\delta$-cadinene, was studied against Candida albicans. The essential oil was active against this strain with a MIC value of $2.0 \mathrm{mg} / \mathrm{mL}$ [26].

Salah et al. (2006) investigated the antifungal effect of methanolic extract of this plant from Tunisia against Trichophyton mentagrophytes var. mentagrophytes, Trichophyton mentagrophytes var. interdigitale, Trichophyton rubrum, Trichophyton soudanense, Microsporum canis, Microsporum gypseum, Epidermophyton floccosum, Aspergillus fumigatus, Scopulariopsis brevicaulis, Scytalidium dimidiatum, C. albicans, and Cryptococcus neoformans [75]. This study was realized using the agar incorporation method and evaluated using two methods: by calculating the percentage inhibition (\% $\%$ and determining the MIC. Variable antifungal activity has been reported of the tested methanolic extract (0-100\% for \% I, and 500 to $>1000 \mu \mathrm{g} / \mathrm{mL}$ for MIC). The most sensitive strain was observed for dermatophytes T. rubrum, T. soudanense, and $M$. canis with an inhibition growth of $100 \%$ and MIC values of $500 \mu \mathrm{g} / \mathrm{mL}$ while hyphamycets (A. fumigatus, $S$. brevicaulis) and pathogenic yeasts $(C$. albicans, and $C$. neoformans) were resistance for this extract. The potent antifungal properties of essential oil and extracts of $S$. verbenaca highlighted that several bioactive compounds could 
be further isolated, tested, and developed into antifungal drugs. However, further, in vivo preclinical tests should be conducted to ensure the safety and efficacy of these essential oils, extracts, and bioactive compounds.

Table 4. Antifungal activity of $S$. verbenaca.

\begin{tabular}{|c|c|c|c|c|c|}
\hline $\begin{array}{l}\text { Part } \\
\text { used }\end{array}$ & $\begin{array}{l}\text { Extract } \\
\text { tested }\end{array}$ & Method used & Tested strains & Keys results & References \\
\hline $\begin{array}{l}\text { Aerial } \\
\text { parts }\end{array}$ & Essential oil & - & Candida albicans & $\mathrm{MIC}=2.0 \mathrm{mg} / \mathrm{mL}$ & {$[26]$} \\
\hline \multirow[t]{12}{*}{-} & \multirow[t]{12}{*}{$\begin{array}{l}\text { Methanolic } \\
\text { extract }\end{array}$} & \multirow{12}{*}{$\begin{array}{l}\text { Agar } \\
\text { incorporation } \\
\text { method }\end{array}$} & $\begin{array}{l}\text { Trichophyton mentagrophytes } \\
\text { var. mentagrophytes }\end{array}$ & $\begin{array}{l}\mathrm{I}=13 \% \\
\mathrm{MIC}=900 \mu \mathrm{g} / \mathrm{mL}\end{array}$ & \multirow[t]{12}{*}{ [75] } \\
\hline & & & $\begin{array}{l}\text { Trichophyton mentagrophytes } \\
\text { var. interdigitale }\end{array}$ & $\begin{array}{l}\mathrm{I}=10 \% \\
\mathrm{MIC}=950 \mu \mathrm{g} / \mathrm{mL}\end{array}$ & \\
\hline & & & Trichophyton rubrum & $\begin{array}{l}\mathrm{I}=100 \% \\
\mathrm{MIC}=500 \mu \mathrm{g} / \mathrm{mL}\end{array}$ & \\
\hline & & & Trichophyton soudanense & $\begin{array}{l}\mathrm{I}=100 \% \\
\mathrm{MIC}=500 \mu \mathrm{g} / \mathrm{mL}\end{array}$ & \\
\hline & & & Microsporum canis & $\begin{array}{l}\mathrm{I}=100 \% \\
\mathrm{MIC}=500 \mu \mathrm{g} / \mathrm{mL}\end{array}$ & \\
\hline & & & Microsporum gypseum & $\begin{array}{l}\mathrm{I}=17 \% \\
\mathrm{MIC}=900 \mu \mathrm{g} / \mathrm{mL}\end{array}$ & \\
\hline & & & Epidermophyton floccosum & $\begin{array}{l}\mathrm{I}=24 \% \\
\mathrm{MIC}=850 \mu \mathrm{g} / \mathrm{mL}\end{array}$ & \\
\hline & & & Aspergillus fumigatus & $\begin{array}{l}\mathrm{I}=0 \% \\
\mathrm{MIC}>1000 \mu \mathrm{g} / \mathrm{mL}\end{array}$ & \\
\hline & & & Scopulariopsis brevicaulis & $\begin{array}{l}\mathrm{I}=0 \% \\
\mathrm{MIC}>1000 \mu \mathrm{g} / \mathrm{mL}\end{array}$ & \\
\hline & & & Scytalidium dimidiatum & $\begin{array}{l}\mathrm{I}=7.5 \% \\
\mathrm{MIC}>1000 \mu \mathrm{g} / \mathrm{mL}\end{array}$ & \\
\hline & & & Candida albicans & $\begin{array}{l}\mathrm{I}=0 \% \\
\mathrm{MIC}>1000 \mu \mathrm{g} / \mathrm{mL}\end{array}$ & \\
\hline & & & Cryptococcus neoformans & $\begin{array}{l}\mathrm{I}=0 \% \\
\mathrm{MIC}>1000 \mu \mathrm{g} / \mathrm{mL}\end{array}$ & \\
\hline
\end{tabular}

3.5.3. Antioxidant activity.

Several studies revealed that Salvia species have an interesting potential for antioxidant activity, which made them one of the interesting sources of natural antioxidants that could provide a chemical basis in the food and pharmaceutical field $[84,85]$. The in vitro antioxidant activity of $S$. verbenaca extracts was studied by many researchers [21,25,76,87-90] (Table 5). In a study conducted by Salah and co-workers (2006), the methanolic extracts of $S$. verbenaca aerial part from Tunisia were tested for their antioxidant effect using DPPH and ABTS assays [76]. The methanolic extract showed a potent antioxidant effect with values of IC50 $=86.9$ $\mu \mathrm{g} / \mathrm{mL}, \mathrm{IC} 50=777.3 \mu \mathrm{g} / \mathrm{mL}$ at $5 \mathrm{~min}, \mathrm{IC} 50=499.5 \mu \mathrm{g} / \mathrm{mL}$ at $20 \mathrm{~min}$, in DPPH, and ABTS, respectively. In the same year, another study investigated the antioxidant effect of $S$. verbenaca hydormethanolic extract towards linoleic acids, linolenic acids, and low-density lipoproteins (LDL) peroxidation. At $100 \mu \mathrm{g} / \mathrm{mL}$, this extract showed significant inhibition of oxygen consumption, conjugated dienes (CD) formation of LDL peroxidation, and thiobarbituric acid reactive substances (TBARS) $(92 \%, 92 \%$, and 93\%, respectively), which was correlated with phenolic compounds present in S. verbenaca extract [86]. In 2008, the antioxidant activity of the methanol extract of Turkish $S$. virgata, S. staminea, and S.verbenaca was investigated using DPPH and $\beta$-carotene assays by Tepe (2008) [87]. It showed that the extract from $S$. verbenaca exerted the most important antioxidant activity with an IC50 value of $14.30 \pm 1.42 \mu \mathrm{g} / \mathrm{mg}$, and 
inhibition of $77.03 \pm 0.42 \%$ in DPPH and $\beta$-Carotene test, respectively. Ben Farhat et al. (2013) tested the antioxidant activity of the methanolic extract of Tunisian $S$. verbenaca collected from ten different habitats using DPPH, ABTS, and FRAP assays [88]. The methanolic extract from $S$. verbenaca collected from Bir Mroua showed interesting antioxidant effect $($ IC50 $=205.27 \pm 0.29 \mu \mathrm{M}$ TE/mg for ABTS assay and IC50 $=159.25 \pm 2.89 \mathrm{mM}$ $\mathrm{Fe}(\mathrm{II}) / \mathrm{mg}$ for FRAP assay) compared with $S$. verbenaca collected from Enfida (IC50 =165.28 $\pm 10.80 \mu \mathrm{M} \mathrm{TE} / \mathrm{mg}$ for ABTS assay and IC50 = 106.50 $\pm 2.20 \mathrm{mM} \mathrm{Fe(II)/mg} \mathrm{for} \mathrm{FRAP} \mathrm{assay)}$ while, using DPPH assay, the antioxidant effect of $S$. verbenaca harvested from Enfida was IC50 $=36.28 \pm 0.01 \mu \mathrm{g} / \mathrm{mL}$ compared with the methanolic extract collected from Bir Mroua (IC50 $=23.00 \pm 0.46 \mu \mathrm{g} / \mathrm{mL}$ ). Furthermore, the authors reported that the antioxidant effect was significantly correlated with the presence of polyphenolic compounds, especially with rosmarinic acid. A significant correlation with DPPH and FRAP was attributed to naringin and with ABTS to gallic acid [88]. A recent study demonstrated that the plant's habitat or origin could impact the biological activities and plant composition and the altitude since the main four chemicals that they identified were affected [68]. The same group conducted by Ben Farhat and co-workers (2015) evaluated the Tunisian S. verbenaca methanolic extracts in three phenological stages for their antiradical effect [25]. This antiradical effect was studied using numerous methods such as DPPH, ABTS, and FRAP assays. The authors showed that this extract has a potent antioxidant effect at the early fruiting period $(49.22 \mu \mathrm{g} / \mathrm{mL}, 146.86 \mu \mathrm{M}$ $\mathrm{TE} / \mathrm{mg}$, and $188.93 \mathrm{mM} \mathrm{Fe}(\mathrm{II}) / \mathrm{mg}$ for DPPH, ABTS, and FRAP, respectively) and evidenced the significant effect of phenophase on antioxidant activity. Nassar et al. (2015) investigated the antioxidant effect of $S$. verbenaca (Algeria) n-BuOH extract using DPPH assay and showed an IC50 $=47,50 \mu \mathrm{g} / \mathrm{mL}$ [23]. In another study, the supercritical carbon dioxide extract, ethanol extract, and aqueous extract of $S$. verbenaca were tested for their in vitro antioxidant activity by Šulniūtè et al. (2016) using ABTS, and ORAC (Oxygen radical absorbance capacity) assays [89]. The aqueous extract showed potent antiradical activity compared with ethanol extract $(\mathrm{IC} 50=69.6 \pm 1.4 \mu \mathrm{mol} \mathrm{TE} / \mathrm{g}$ vs. IC50 $=1742 \pm 2.3 \mu \mathrm{mol} \mathrm{TE} / \mathrm{g}$ for ABTS assay and IC50 = $626 \pm 34.2 \mu \mathrm{mol} \mathrm{TE} / \mathrm{g}$ vs. IC50 $=4121 \pm 300.7 \mu \mathrm{mol} \mathrm{TE} / \mathrm{g}$ for ORAC assay). Belkhiri et al. (2017) evaluated the antioxidant effect of ethyl acetate extract, chloroform extract, aqueous extract, and crude extract of $S$. verbenaca aerial part (Algeria) using ferrous iron chelating assay and DPPH free radical scavenging [21]. The ethyl acetate extract was the most active extract in reducing power assay (EC50 $=0.0047 \pm 0.000 \mathrm{mg} / \mathrm{ml}$ ) and in DPPH radical scavenging assay (IC50 $=0.0086 \pm 0.000 \mathrm{mg} / \mathrm{ml}$ ). Recently, the aqueous extract and the methanolic extract of aerial parts of $S$. verbenaca from Algeria have been investigated for their in vitro antioxidant properties using DPPH radical scavenging, ABTS radical scavenging, alkaline DMSO superoxide radical scavenging, $\beta$-carotene bleaching assays. From this study, all extracts showed a comparison with butylhydroxytoluene (BHT) as a positive control. Recently, Nassar and coworkers (2020) investigated in vitro the protective activities of the methanolic extract from $S$. verbenaca root against oxidative stress induced by $\mathrm{H}_{2} \mathrm{O}_{2}$ by measuring the intracellular ROS level using the 2,7-dichlorodihydrofluorescien diacetate (H2DCFDA) assay [90]. At $10 \mu \mathrm{g} / \mathrm{L}$, the methanolic extract with $\mathrm{H}_{2} \mathrm{O}_{2}$ showed a significant decrease in the intracellular ROS level. In 2021, Righi et al. (2021) investigated the antioxidant effect of hydromethanolic extract of $S$. verbenaca (Algeria) using DPPH, AAPH, iron chelating, and FRAP assays and showed an $\mathrm{IC}_{50}=7.6 \pm 0.6 \mu \mathrm{g} / \mathrm{mL}, \mathrm{IC}_{50}=111.1 \pm 8 \mu \mathrm{g} / \mathrm{mL}$, $\mathrm{IC}_{50}=189.2 \pm 7.9 \mu \mathrm{g} / \mathrm{mL}$, and $4.3 \pm 0.1 \mathrm{mmol}$ FeSO4 Eq./g, respectively [91]. Diterpenoids and rosmarinic acid were the most characterized compounds of Salvia species, and they were 
confirmed to be the actors in many biological activities, especially the antioxidant effect. It was shown that $S$. verbenaca methanolic extract had the highest level of rosmarinic acid $(29.30 \pm$ $0.24 \mu \mathrm{g} / \mathrm{mg}$ ) compared to $S$. virgate and S. staminea [79,85,92]. Indeed, several in vitro investigations illustrated the correlation between phenolic compounds and antioxidant activities and with the synergy effect with other compounds $[93,94]$.

Table 5. Antioxidant activity of S. verbenaca.

\begin{tabular}{|c|c|c|c|c|}
\hline Use part & Extracts & Used method & Key results & References \\
\hline \multirow[t]{4}{*}{ Aerial parts } & Ethyl acetate extract & \multirow[t]{4}{*}{$\begin{array}{l}\text { Ferrous iron-chelating assay, } \\
\text { and DPPH free radical } \\
\text { scavenging, respectively }\end{array}$} & $\begin{array}{l}\mathrm{EC}_{50}=0.0047 \pm 0.000 \\
\mathrm{mg} / \mathrm{mL} \\
\mathrm{IC}_{50}=0.0086 \pm 0.000 \\
\mathrm{mg} / \mathrm{mL}\end{array}$ & \multirow[t]{4}{*}[21]{} \\
\hline & Chloroform extract & & $\begin{array}{l}\mathrm{EC}_{50}=0.453 \pm 0.0006 \\
\mathrm{mg} / \mathrm{mL} \\
\mathrm{IC}_{50}=0.0725 \mathrm{mg} / \mathrm{mL}\end{array}$ & \\
\hline & Aqueous extract & & $\begin{array}{l}\mathrm{EC}_{50}=0.0455 \pm 0.000 \\
\mathrm{mg} / \mathrm{mL} \\
\mathrm{IC}_{50}=0.0389 \mathrm{mg} / \mathrm{mL}\end{array}$ & \\
\hline & Crude extract & & $\begin{array}{l}\mathrm{EC}_{50}=0.0178 \pm 0.000 \\
\mathrm{mg} / \mathrm{mL} \\
\mathrm{IC}_{50}=0.0336 \mathrm{mg} / \mathrm{mL}\end{array}$ & \\
\hline \multirow[t]{3}{*}{ Aerial parts } & \multirow[t]{3}{*}{ Methanolic extracts } & DPPH & $\mathrm{IC}_{50}=23.00 \pm 0.46 \mu \mathrm{g} / \mathrm{mL}$ & \multirow[t]{3}{*}[88]{} \\
\hline & & ABTS & $\begin{array}{l}\mathrm{IC}_{50}=205.27 \pm 0.29 \mu \mathrm{M} \\
\mathrm{TE} / \mathrm{mg}\end{array}$ & \\
\hline & & FRAP & $\begin{array}{l}\mathrm{IC}_{50}=159.25 \pm 2.89 \mu \mathrm{M} \\
\mathrm{Fe}(\mathrm{II}) / \mathrm{mg}\end{array}$ & \\
\hline \multirow[t]{3}{*}{ Aerial parts } & \multirow[t]{3}{*}{ Methanolic extract } & DPPH & $\begin{array}{l}\mathrm{IC}_{50}=107.71 \pm 4.18 \\
\mu \mathrm{g} / \mathrm{mL} \text { for flowering stage } \\
\mathrm{IC}_{50}=49.22 \pm 1.10 \mu \mathrm{g} / \mathrm{mL} \\
\text { for early fruiting stage } \\
\mathrm{IC}_{50}=69.66 \pm 2.35 \mu \mathrm{g} / \mathrm{mL} \\
\text { for late fruiting stage }\end{array}$ & \multirow[t]{3}{*}[25]{} \\
\hline & & ABTS & $\begin{array}{l}\mathrm{IC}_{50}=102.37 \pm 2.04 \mu \mathrm{M} \\
\mathrm{TE} / \mathrm{mg} \text { for flowering stage } \\
\mathrm{IC}_{50}=146.86 \pm 5.44 \mu \mathrm{M} \\
\mathrm{TE} / \mathrm{mg} \text { for early fruiting } \\
\text { stage } \\
\mathrm{IC}_{50}=116.80 \pm 4.70 \mu \mathrm{M} \\
\mathrm{TE} / \mathrm{mg} \text { for late fruiting } \\
\text { stage }\end{array}$ & \\
\hline & & FRAP & $\begin{array}{l}\mathrm{IC}_{50}=106.00 \pm 5.29 \mathrm{mM} \\
\mathrm{Fe}(\mathrm{II}) / \mathrm{mg} \text { for flowering } \\
\text { stage } \\
\mathrm{IC}_{50}=188.93 \pm 8.86 \mathrm{mM} \\
\mathrm{Fe}(\mathrm{II}) / \mathrm{mg} \text { for early fruiting } \\
\text { stage } \\
\mathrm{IC}_{50}=127.33 \pm 2.42 \mathrm{mM} \\
\mathrm{Fe}(\mathrm{II}) / \mathrm{mg} \text { for late fruiting } \\
\text { stage }\end{array}$ & \\
\hline \multirow[t]{3}{*}{ Aerial parts } & \multirow[t]{3}{*}{$\begin{array}{l}\text { Hydromethanolic } \\
\text { extract }\end{array}$} & $\begin{array}{l}\text { Conjugated dienes (CD) } \\
\text { formation }\end{array}$ & Inhibition $=92 \%$ & \multirow[t]{3}{*}[86]{} \\
\hline & & Oxygen consumption & Inhibition $=92 \%$ & \\
\hline & & $\begin{array}{l}\text { Thiobarbituric acid reactive } \\
\text { substances (TBARS) }\end{array}$ & Inhibition $=93 \%$ & \\
\hline \multirow[t]{4}{*}{ Aerial parts } & \multirow[t]{4}{*}{ Methanol extract } & ABTS radical scavenging & $\mathrm{IC}_{50}=19.96 \pm 1.03 \mu \mathrm{g} / \mathrm{mL}$ & \multirow[t]{4}{*}{ [95] } \\
\hline & & $\begin{array}{l}\text { Alkaline DMSO superoxide } \\
\text { radical scavenging }\end{array}$ & $\mathrm{IC}_{50}=07.77 \pm 1.00 \mu \mathrm{g} / \mathrm{mL}$ & \\
\hline & & $\beta$-carotene bleaching & $\mathrm{I}=82.58 \pm 2.39 \%$ & \\
\hline & & DPPH & $\mathrm{IC}_{50}=24.36 \pm 1.13 \mu \mathrm{g} / \mathrm{mL}$ & \\
\hline
\end{tabular}




\begin{tabular}{|c|c|c|c|c|}
\hline Use part & Extracts & Used method & Key results & References \\
\hline & \multirow[t]{4}{*}{ Aqueous exract } & ABTS radical scavenging & $\mathrm{IC}_{50}=36.86 \pm 1.03 \mu \mathrm{g} / \mathrm{mL}$ & \\
\hline & & $\begin{array}{l}\text { Alkaline DMSO superoxide } \\
\text { radical scavenging }\end{array}$ & $\mathrm{IC}_{50}=18.78 \pm 1.11 \mu \mathrm{g} / \mathrm{mL}$ & \\
\hline & & $\beta$-carotene bleaching & $\mathrm{I}=96.12 \pm 2.48 \%$ & \\
\hline & & DPPH & $\mathrm{IC}_{50}=27.26 \pm 1.05 \mu \mathrm{g} / \mathrm{mL}$ & \\
\hline Aerial parts & n-BuOH extract & DPPH & $\mathrm{IC}_{50}=47,50 \mu \mathrm{g} / \mathrm{mL}$ & {$[23]$} \\
\hline Root & Methanol extract & $\begin{array}{l}2,7- \\
\text { Dichlorodihydrofluorescien } \\
\text { diacetate (H2DCFDA) assay }\end{array}$ & $\mathrm{I}>150 \%$ at $10 \mu \mathrm{g} / \mathrm{mL}$ & {$[90]$} \\
\hline \multirow[t]{4}{*}{ Aerial parts } & \multirow{4}{*}{$\begin{array}{l}\text { Hydromethanol } \\
\text { extract }\end{array}$} & DPPH & $\mathrm{IC}_{50}=7.6 \pm 0.6 \mu \mathrm{g} / \mathrm{mL}$ & \multirow[t]{4}{*}[91]{} \\
\hline & & AAPH & $\mathrm{IC}_{50}=111.1 \pm 8 \mu \mathrm{g} / \mathrm{mL}$ & \\
\hline & & Iron chelating & $\mathrm{IC}_{50}=189.2 \pm 7.9 \mu \mathrm{g} / \mathrm{mL}$ & \\
\hline & & FRAP & $\begin{array}{l}4.3 \pm 0.1 \mathrm{mmol} \mathrm{FeSO} 4 \\
\text { Eq./g }\end{array}$ & \\
\hline \multirow[t]{2}{*}{ Aerial parts } & \multirow[t]{2}{*}{ Methanol extract } & DPPH & $\mathrm{IC}_{50}=86.9 \mu \mathrm{g} / \mathrm{mL}$ & \multirow[t]{2}{*}[75]{} \\
\hline & & ABTS & $\begin{array}{l}\mathrm{IC}_{50}=777.3 \mu \mathrm{g} / \mathrm{mL} \text { at } 5 \\
\min \\
\mathrm{IC}_{50}=499.5 \mu \mathrm{g} / \mathrm{mL} \text { at } 20 \\
\min \end{array}$ & \\
\hline \multirow{6}{*}{$\begin{array}{l}\text { Not } \\
\text { mentionned }\end{array}$} & \multirow{2}{*}{$\begin{array}{l}\text { Supercritical carbon } \\
\text { dioxide extract }\end{array}$} & ABTS & - & \multirow[t]{6}{*}[99]{} \\
\hline & & ORAC & $\begin{array}{l}\mathrm{IC}_{50}=1142 \pm 38.7 \mu \mathrm{mol} \\
\mathrm{TE} / \mathrm{g}\end{array}$ & \\
\hline & \multirow[t]{2}{*}{ Ethanol extract } & ABTS & $\begin{array}{l}\mathrm{IC}_{50}=1742 \pm 2.3 \mu \mathrm{mol} \\
\mathrm{TE} / \mathrm{g}\end{array}$ & \\
\hline & & ORAC & $\begin{array}{l}\mathrm{IC}_{50}=4121 \pm 300.7 \mu \mathrm{mol} \\
\mathrm{TE} / \mathrm{g}\end{array}$ & \\
\hline & \multirow[t]{2}{*}{ Aqueous extract } & ABTS & $\begin{array}{l}\mathrm{IC}_{50}=69.6 \pm 1.4 \mu \mathrm{mol} \\
\mathrm{TE} / \mathrm{g}\end{array}$ & \\
\hline & & ORAC & $\begin{array}{l}\mathrm{IC}_{50}=626 \pm 34.2 \mu \mathrm{mol} \\
\mathrm{TE} / \mathrm{g}\end{array}$ & \\
\hline \multirow{2}{*}{$\begin{array}{l}\text { Not } \\
\text { mentionned }\end{array}$} & \multirow[t]{2}{*}{ Methanol extract } & DPPH & $\mathrm{IC}_{50}=14.30 \pm 1.42 \mu \mathrm{g} / \mathrm{mg}$ & \multirow[t]{2}{*}[87]{} \\
\hline & & $\beta$-Carotene & $\begin{array}{l}\text { Inhibition }=77.03 \pm 0.42 \\
\%\end{array}$ & \\
\hline
\end{tabular}

\subsubsection{Anticancer activity.}

The anticancer activity of essential oils and different extracts of $S$. verbenaca was conducted against several cancer cells using different methods [20,78,96,97]. Table 6 summarized all research that evaluated the cytotoxicity effect of $S$. verbenaca, including the part used, the extract tested, the method used, and the main results.

Organic extracts of different parts from $S$. verbenaca against anticancer cells were widely evaluated. Badisa et al. (2005) evaluated the anticancer activity of the aerial parts of $S$. verbenaca methanolic extract (Greece) at different concentrations (10-100 $\mu \mathrm{g} / \mathrm{mL}$ ) against four human cell lines, namely human colon adenocarcinoma (HCA), human hepatoblastoma (HepG2), human breast cancer cells (MCF-7), and human pancreatic carcinoma (HPC) using brine shrimp lethality assay [96]. The result showed that this extract exhibited a lethal concentration $\mathrm{LC}_{50}>75 \mu \mathrm{g} / \mathrm{mL}$ in all cell lines tested. At the same time, there was a low cytotoxic effect of this extract against normal mouse adipose areolar cell line (NCTC clone 929) with $12 \%$ of death at $0.1 \mathrm{mg} / \mathrm{mL}$. Furthermore, the same extract was investigated in vivo for cytotoxic activity against brine shrimps and found to be highly active with ED50 $<300$ $\mu \mathrm{g} / \mathrm{mL}$. Leaves methanolic extracts of this plant collected from Riyadh (Kingdom of Saudi Arabia) showed the highest activity against Vero cells $\left(\mathrm{CC}_{50}=73.65 \mu \mathrm{g} / \mathrm{mL}\right)$ compared with human larynx cancer cells (HEp-2 cells) $\left(\mathrm{CC}_{50}=114.36 \mu \mathrm{g} / \mathrm{mL}\right)$ [97]. In 2018, the anticancer activity of three organic extracts of $S$. verbenaca aerial parts from Ain Aouda (Rabat, Morocco) 
was investigated. Hexane, ethyl acetate, and n-butanol extracts were evaluated in vitro against Human Embryonal Rhabdomyosarcoma cancerous cell lines (RD) and Monkey kidney cancerous cell lines (Vero) using MTT assay [20]. These authors reported that all extracts exhibited a weak cytotoxicity activity ( $\mathrm{IC}_{50}>500 \mu \mathrm{g} / \mathrm{mL}$ ) except for ethyl acetate extract, which presented an $\mathrm{IC}_{50}$ value of $223.63 \pm 1.61 \mu \mathrm{g} / \mathrm{mL}$. Moreover, ethyl acetate extract of $S$. verbenaca leaves (from Jordan) showed the highest activity against MDA MB-231 breast cancer cells with an $\mathrm{IC}_{50}=41.3 \pm 4.8 \mu \mathrm{g} / \mathrm{mL}$ using a low concentration of ethyl acetate extract (10-100 $\mu \mathrm{g} / \mathrm{mL})$ [78]. The variability of the phytochemical composition of each extract could be the main cause of the different cytotoxicity observed.

Few studies investigated the anticancer activity of $S$. verbenaca essential oils. Russo et al. (2015) studied in vitro antitumor effect of essential oils of $S$. verbenaca aerial parts collected from Sicily (Italia) with those cultivated in the Botanical Gardens of Palermo [27]. The cytotoxic activity was carried out on human melanoma cells (M14) using the MTT assay. The essential oil exhibited a potent antiproliferative effect of both $S$. verbenaca wild and cultivated with an $\mathrm{IC}_{50}$ value of $12.2 \pm 0.4 \mu \mathrm{g} / \mathrm{mL}$, and $8.1 \pm 0.6 \mu \mathrm{g} / \mathrm{mL}$, respectively. The slight variation observed in the same species is due to localization growth, climate, light, nutrient variability, and seasons resulting in the chemical variation of the essential oil [95]. In this study, the authors reported that sesquiterpene compounds possess an anticancer potential by caspase- 3 activity [65]. Furthermore, essential oil from $S$. verbenaca cultivated presents a high concentration of carvacrol. This phenolic compound inhibited the growth of melanoma cells [27] and has been reported recently for its action in the different molecular mechanisms through the alteration of soluble factors and the inhibition of protein expressions (PI3K/p-AKT) $[98,99]$. The essential oil of $S$. verbenaca exhibited a potent in vitro anticancer activity, which can be possible to use in the pharmaceutical industry. However, this effect should be in-depth validated in vivo to exploit the mechanistic pathways and the bioactive compounds responsible for the action.

\begin{tabular}{|c|c|c|c|c|c|}
\hline Part used & Extract tested & $\begin{array}{l}\text { Methods } \\
\text { used }\end{array}$ & Tested strains & Keys results & References \\
\hline Leaves & Ethyl acetate & - & MDA MB-231 & $\mathrm{IC}_{50}=41.3 \pm 4.8 \mu \mathrm{g} / \mathrm{mL}$ & {$[78]$} \\
\hline \multirow[t]{5}{*}{ Aerial parts } & \multirow[t]{5}{*}{$\begin{array}{l}\text { Methanol } \\
\text { extract }\end{array}$} & $\begin{array}{l}\text { Shrimps } \\
\text { assay }\end{array}$ & $\begin{array}{l}\text { Brine shrimps } \\
\text { larvae }\end{array}$ & $\mathrm{ED}_{50}<300 \mu \mathrm{g} / \mathrm{mL}$ & \multirow[t]{5}{*}{ [96] } \\
\hline & & \multirow[t]{4}{*}{-} & HCA & $\mathrm{LC}_{50}>75 \mu \mathrm{g} / \mathrm{mL}$ & \\
\hline & & & HepG2 & $\mathrm{LC}_{50}>75 \mu \mathrm{g} / \mathrm{mL}$ & \\
\hline & & & $\mathrm{MCF}-7$ & $\mathrm{LC}_{50}>75 \mu \mathrm{g} / \mathrm{mL}$ & \\
\hline & & & HPC & $\mathrm{LC}_{50}>75 \mu \mathrm{g} / \mathrm{mL}$ & \\
\hline \multirow[t]{6}{*}{ Aerial parts } & \multirow[t]{2}{*}{ Hexane } & \multirow[t]{6}{*}{ MTT assay } & $\mathrm{RD}$ & $\mathrm{IC}_{50}=474.62 \pm 1.31 \mu \mathrm{g} / \mathrm{mL}$ & \multirow[t]{6}{*}[20]{} \\
\hline & & & Vero & $\mathrm{IC}_{50}>500 \mu \mathrm{g} / \mathrm{mL}$ & \\
\hline & \multirow[t]{2}{*}{ Ethyl acetate } & & $\mathrm{RD}$ & $\mathrm{IC}_{50}>500 \mu \mathrm{g} / \mathrm{mL}$ & \\
\hline & & & Vero & $\mathrm{IC}_{50}=223.63 \pm 1.61 \mu \mathrm{g} / \mathrm{mL}$ & \\
\hline & \multirow[t]{2}{*}{ n-butanol } & & $\mathrm{RD}$ & $\mathrm{IC}_{50}>500 \mu \mathrm{g} / \mathrm{mL}$ & \\
\hline & & & Vero & $\mathrm{IC}_{50}>500 \mu \mathrm{g} / \mathrm{mL}$ & \\
\hline \multirow[t]{2}{*}{ Leaves } & \multirow{2}{*}{$\begin{array}{l}\text { Methanol } \\
\text { extract }\end{array}$} & \multirow[t]{2}{*}{ CTB assay } & Vero & $\mathrm{CC}_{50}=73.65 \mu \mathrm{g} / \mathrm{mL}$ & \multirow[t]{2}{*}{ [97] } \\
\hline & & & HEp-2 & $\mathrm{CC}_{50}=114.36 \mu \mathrm{g} / \mathrm{mL}$ & \\
\hline Aerial parts & $\begin{array}{l}\text { Essential oil } \\
(0.25 \%)\end{array}$ & MTT assay & M14 & $\begin{array}{l}\mathrm{IC}_{50}=12.2 \pm 0.4 \mu \mathrm{g} / \mathrm{mL} \text { for } S . \\
\text { verbenaca } \text { wild } \mathrm{IC}_{50}=8.1 \pm 0.6 \\
\mu \mathrm{g} / \mathrm{mL} \text { for } S . \text { verbenaca } \text { cultivate }\end{array}$ & {$[27]$} \\
\hline
\end{tabular}

3.5.5. Antileishmanial activity.

As reported by World Health Organization, more than 20 protozoan species of the genus Leishmania caused leishmaniasis. The bite of infected sandflies transmits this disease. Cutaneous and visceral leishmaniasis, forms of this disease, is the most serious form, leading to death if untreated [100]. Due to the increase of the resistance of parasites against current 
therapies and the lack of vaccines against Leishmania spp., the researchers are particularly interested in developing urgent new treatments [101]. Natural products from medicinal plants showed an interesting antileishmanial property and present potential leads in treating this disease [102]. In 2016, three solvent partitions (methanol, n-hexane, and dichloromethane) of S. verbenaca were tested by Et-Touys and coworkers (2016) against three promastigote forms Leishmania major, Leishmania tropica, and Leishmania infantum [103]. The dichloromethane partition showed better activity with $\mathrm{IC}_{50}$ values ranging from 24.56 to $33.77 \mu \mathrm{g} / \mathrm{mL}$. The nhexane extract showed the most active effect against Leishmania infantum $\left(\mathrm{IC}_{50}=14.11\right.$ $\mu \mathrm{g} / \mathrm{mL}$ ), whereas lower activity against Leishmania major, and Leishmania tropica has been observed $\left(\mathrm{IC}_{50}=155.43 \mu \mathrm{g} / \mathrm{mL}\right.$, and $\mathrm{IC}_{50}=148.23 \mu \mathrm{g} / \mathrm{mL}$, respectively). The methanolic extract did not exhibit antileishmanial activity against any of the tested parasites. From this study, the authors suggested that extracts act through walls and membrane disruption by the lipophilic compounds [103].

\subsubsection{Antidiabetic activity.}

The antidiabetic effect of $S$. verbenaca was reported for the first time by Mamach and coworkers (2020) [96]. One promising strategy to reduce glucose absorption is by inhibiting enzymes implicated in intestinal hydrocarbons catabolism, such as $\alpha$-amylase and $\alpha$ glucosidase. In a recent study, Mamach et al. (2020) evaluated the inhibitory effect of $S$. verbenaca (Algeria) aqueous and methanolic extracts against $\alpha$-amylase and $\alpha$-glucosidase enzymes. They showed that the methanolic extracts of $S$. verbenaca (aerial part) inhibited $\alpha-$ amylase and $\alpha$-glucosidase ( $\mathrm{IC}_{50}=101.30 \mu \mathrm{g} / \mathrm{mL}$, and $\mathrm{IC}_{50}=150.5 \mu \mathrm{g} / \mathrm{mL}$, respectively), while the aqueous extract was no active against $\alpha$-amylase and inhibited $\alpha$-glucosidase with an $\mathrm{IC}_{50}$ $>300 \mu \mathrm{g} / \mathrm{mL}$ [95]. In this study, the authors suggested that phenols such as caffeic acid, curcumin, hesperetin, cyanidin, naringenin, and quercetin can inhibit the $\alpha$-amylase and $\alpha$ glucosidase enzyme.

\subsubsection{Anti-inflammatory activity.}

Bioactive compounds have an anti-inflammatory effect by inhibiting the release of lysosomal enzymes and stabilizing the lysosomal membranes. In this context, Righi and coworkers (2021) tested ex vivo the capacity of hydromethanolic extract of $S$. verbenaca to protect the cell membrane of mice erythrocytes from hypotonic and heat-induced hemolysis [91]. At $400 \mu \mathrm{g} / \mathrm{mL}$, the hydromethanolic extract exerted relevant protection of erythrocytes against hemolysis induced by heat and hypotonic conditions, with a maximum inhibition percentage of $78 \%$ and $69 \%$, respectively. Furthermore, this extract has the ability to inhibit erythrocytes' hemolysis with an IC50 value of $30 \mu \mathrm{g} / \mathrm{mL}$. In this study, the authors suggested that some compounds in $S$. verbenaca bonded to the erythrocyte's membranes with subsequent alteration of the surface charges of the cells [91]. They also investigated in vivo the antiinflammatory effect of $S$. verbenaca hydromethanolic extract using xylene-induced ear edema as an acute inflammation model. Using the hydromethanol extract at different concentrations (200-600 $\mathrm{mg} / \mathrm{kg} \mathrm{bw}$ ), the ear weight caused by xylene has been reduced with maximal percentage reaching $50 \%$ of inhibition at the highest dose $(600 \mathrm{mg} / \mathrm{kg} \mathrm{bw})$. The authors suggested that the anti-edematogenic effect attributed to phenolic compounds and triterpenoids present in S. verbenaca, mainly rosmarinic acid, caffeoylmalic acid, and luteolin [91]. Rosmarinic acid modulated inflammation by inhibition of neutrophil infiltration and regulation 
of ICAM-1 (Intercellular Adhesion Molecule 1), VCAM-1 (vascular cell adhesion molecule 1), and cyclooxygenase-2 [108], while luteolin may also inhibit TNF-induced proinflammatory gene expression in murine intestinal epithelial cells [105].

\subsubsection{Antihemolytic activity.}

Recent research reported the protective biochemical function of extracts from aromatic and medicinal plants on free radicals and their mechanism of action [106]. S. verbenaca aerial part extracts were evaluated for their protection capacity on red blood cells (RBCs) against oxidative damage induced by 2,2,-azobis (2-amidinopropane) dihydrochloride (AAPH). Ethyl acetate extract exhibited the most antihemolytic effect $\left(\mathrm{HT}_{50}=165 \mathrm{~min}\right)$. $S$. verbenaca aerial part extracts significantly protected the erythrocyte membrane from hemolysis in a timedependent manner through the involvement of the phytochemicals. The authors of this study suggested that phytochemicals in $S$. verbenaca trapped the peroxyl radicals in the aqueous phase before they attack the erythrocyte membrane's lipid molecules, thus protecting against lipid peroxidation. Thus, the free radical chain reaction is broken and subsequent oxidative hemolysis is inhibited [21].

\subsubsection{Antihypertensive activity.}

In 2005, Ahmed and coworkers (2005) isolated three flavonoids from S. verbenaca, namely 5-hydroxy-3,4',7-trimethoxyflavone, retusin, and verbenacoside, and investigated their antihypertensive activity in normotensive albino rats [4]. At a dose of $3.3 \mathrm{mg} / \mathrm{kg}, 5$-hydroxy-3, 4', 7-trimethydoxyflavone, and verbenacoside showed the most potent effect in decreasing the blood pressure with a value of $30.0 \mathrm{mmHg}$, and $13.2 \mathrm{mmHg}$, respectively and in decreasing in heart rate with a value of $28.5 \%$ and $15.4 \%$, respectively. This indicated that the lowering of blood pressure was due to a decrease in heart rate produced by vasodilatation. Likewise, the alcoholic extract of $S$. verbenaca $(0.5 \mathrm{mg} / \mathrm{kg})$ displayed an important decrease in blood pressure (36.2 $\mathrm{mmHg}$ ), and an $18.8 \%$ decrease in heart rate. However, the compounds extracted from S. verbenaca were found to play a major part in lowering blood pressure as well as heart rate [4].

\subsubsection{Skin effect.}

The use of herbal medicines is in growing demand. S. verbenaca is widely used in traditional medicine [107] and has been reported to have many pharmacological properties and beneficial effects on human health [26,86]. In 1998, Bellakhdar (1998) reported that the leaves of $S$. verbenaca are traditionally applied in poultices on wounds and emptied abscesses to facilitate their healing [108]. After twenty years, the first preclinical test of $S$. verbenaca was evaluated in their skin effect. Acute dermal toxicity and sub-chronic dermal toxicity of $S$. verbenaca aerial parts were explored on mice through a single application of extracts at 2000 $\mathrm{mg} / \mathrm{kg}$. Hexane, ethyl acetate, and n-butanol extracts did not show any toxic symptoms and not affected their appetite and general behavior, indicating that their metabolism was not affected by the treatment of the extract [20].

\subsubsection{Immunomodulatory activity.}

Numerous in vitro studies reported that natural antioxidants from plants such as polyphenols play an important role in the protection of cells from oxidative damage and 
consequently induce immunostimulatory effects [109]. S. verbenaca can be used as a potential source of useful drugs due to its richness with flavonoids and tannins [110]. According to Nassar et al. (2015), the immunomodulatory effects of the crude extracts from the aerial parts of $S$. verbenaca proved an immune-stimulatory effect on the reticuloendothelial system [23]. The phagocytic index was increased significantly in animals injected with $S$. verbenaca extracts at doses of $200 \mathrm{mg} / \mathrm{kg}(\alpha=0.095 \pm 1.71)$ compared to the control group. The clearance rate of carbon was faster, and the corrected phagocytic index was increased with $S$. verbenaca.

\subsubsection{Larvicidal activity.}

Synthetic insecticides are today at the fore of mosquito control agents. However, they produce an environmentally ill effect. Besides that, most mosquito species are becoming physiologically resistant and develop high levels of resistance to synthetic control agents $[111,112]$. Plants crude extracts and their compounds display novel insecticidal constituents and provide potential alternatives for the use of synthetic chemical products. According to Pavela (2008), methyl alcohol extracts of $S$. verbenaca stem showed important larvicidal activity against the fourth larval instar of the mosquito Culex quinquefasciatus Say (Diptera: Culicidae) after $24 \mathrm{~h}$ of exposure with the plant extracts in a maximal dose of $500 \mathrm{ppm}$. Methyl alcohol extract exhibited larvicidal activity with $90 \%$ mortality and LD50 value of $311 \mathrm{ppm}$ [113].

\subsubsection{Xanthine oxidase activity.}

Using the colorimetric method, Belkhiri and coworkers (2017) evaluated the activity of xanthine oxidase of ethyl acetate, crud, chloroform, and aqueous extracts of $S$. verbenaca aerial parts collected from Algeria. They investigated xanthine oxidase inhibitory activity by measuring uric acid production at $295 \mathrm{~nm}$. The chloroform extract showed significantly the highest activity followed by ethyl acetate, crud, and aqueous extracts with an IC50 values of $0.009 \mathrm{mg} / \mathrm{ml}, 0.017 \mathrm{mg} / \mathrm{ml}, 0.052 \mathrm{mg} / \mathrm{ml}$, and $0.98 \mathrm{mg} / \mathrm{mL}$, respectively [21]. From this research, the authors suggested that this activity is related to the presence of flavonoids in $S$. verbenaca aerial part extracts and their structural differences. The unsaturation in the $\mathrm{C}$ ring and the free hydroxyl group at C-7 enhanced the activity.

\subsubsection{Toxicological investigation.}

S. verbenaca was widely tested for several pharmacological properties and beneficial effects. However, few studies evaluated its toxicity. Guaouguaou and coworkers (2018) were the first to assess the toxicological effect of $S$. verbenaca [20]. They investigated in vivo the acute and subchronic toxicological effects of $S$. verbenaca extracts (hexane, ethyl acetate, and n-butanol extracts) collected from Ain Aouda (Rabat, Morocco). They observed that the oral administration of all extracts, at a dose of $2000 \mathrm{mg} / \mathrm{kg} \mathrm{b.w}$, did not cause mice mortality within $72 \mathrm{~h}$ and during the 14 days of observation. This indicated that the eventual harmful effects of the investigated extracts are greater than the single high dose recommended by OECD guidelines-423. Two years later, Nassar and investigators (2020) evaluated the cytotoxicity activity of methanolic extract of $S$. verbenaca (Algeria) on human monocytic leukemia cells (THP-1) using thiazolyl blue tetrazolium bromide (MTT) assay [90]. At less than $500 \mu \mathrm{g} / \mathrm{ml}$, the methanolic extract exhibited a non-cytotoxic effect on the cell viability of THP-1 cells, while $500 \mu \mathrm{g} / \mathrm{ml}$ and $1000 \mu \mathrm{g} / \mathrm{ml}$ decreased significantly in the cell viability of THP-1 cells. 
Recently, Righi and coworkers (2021) investigated the toxicity of hydromethanolic extract of S. verbenaca aerial parts (Algeria) on Artemia salina larvae [91]. The result revealed that the hydromethanolic extract exhibited a mortality rate of $A$. salina larvae in a dose-dependent manner. The mortality rate was $17 \%$ at $1 \mu \mathrm{g} / \mathrm{mL}$, and $100 \%$ at $500 \mu \mathrm{g} / \mathrm{mL}$ with LC 50 value of $30 \pm 5.4 \mu \mathrm{g} / \mathrm{ml}$. At the same time, the same group of research assessed in vivo acute and subacute oral toxicity of hydromethanol extract of $S$. verbenaca (Algeria). They evaluated the acute toxicity of the hydromethanol extract of $S$. verbenaca in mice by orally administering a unique limit dose of $2000 \mathrm{mg} / \mathrm{kg}$ body weight for 14 days and the subacute toxicity in mice by administering a daily oral dose of 200,400 , and $800 \mathrm{mg} / \mathrm{kg}$ bw during 21 days. They found that the treatment by gavage did not cause any deaths or side effects. From these data, it can be concluded that the toxicological effect of $S$. verbenaca is scarcely explored. Thus, further preclinical tests are necessary for a safe dose.

Table 7. Other activities of S. verbenaca.

\begin{tabular}{|c|c|c|c|c|c|}
\hline Activities & $\begin{array}{l}\text { Use } \\
\text { part }\end{array}$ & Extracts & Experimental approach & Key results & References \\
\hline \multirow[t]{4}{*}{$\begin{array}{l}\text { Antihemolytic } \\
\text { activity }\end{array}$} & \multirow[t]{4}{*}{$\begin{array}{l}\text { Aerial } \\
\text { parts }\end{array}$} & $\begin{array}{l}\text { Ethyl acetate } \\
\text { extract }\end{array}$ & \multirow{4}{*}{$\begin{array}{l}\text { Oxidative hemolysis induced } \\
\text { by } 2,2, \text {-azobis }(2- \\
\text { amidinopropane) } \\
\text { dihydrochloride }\end{array}$} & $\mathrm{HT}_{50}=165 \mathrm{~min}$ & \multirow[t]{4}{*}[21]{} \\
\hline & & Crud extract & & $\mathrm{HT}_{50}=125.17 \mathrm{~min}$ & \\
\hline & & $\begin{array}{l}\text { Chloroform } \\
\text { extract }\end{array}$ & & $\mathrm{HT}_{50}=111.50 \mathrm{~min}$ & \\
\hline & & Aqueous extract & & $\mathrm{HT}_{50}=111.50 \mathrm{~min}$ & \\
\hline \multirow[t]{3}{*}{$\begin{array}{l}\text { Antihypertensive } \\
\text { activity }\end{array}$} & \multirow[t]{3}{*}{$\begin{array}{l}\text { Aerial } \\
\text { parts }\end{array}$} & $\begin{array}{l}\text { Alcoholic extract } \\
(0.5 \mathrm{mg} / \mathrm{kg})\end{array}$ & \multirow[t]{3}{*}{$\begin{array}{l}\text { Normotensive Wistar albino } \\
\text { rats (NTR) }\end{array}$} & $\begin{array}{l}\text { Decease in } \mathrm{BP}= \\
36.2 \mathrm{mmHg} \\
18.8 \% \text { decrease in } \\
\mathrm{HR}\end{array}$ & \multirow[t]{3}{*}{ [4] } \\
\hline & & $\begin{array}{l}\text { 5-hydroxy-3, 4', } \\
\text { 7- } \\
\text { trimethoxyflavone } \\
(3.3 \mathrm{mg} / \mathrm{kg})\end{array}$ & & $\begin{array}{l}\text { Decease in } \mathrm{BP}= \\
30.0 \mathrm{mmHg} \\
28.5 \% \text { decrease in } \\
\mathrm{HR}\end{array}$ & \\
\hline & & $\begin{array}{l}\text { Verbenacoside } \\
(3.3 \mathrm{mg} / \mathrm{kg})\end{array}$ & & $\begin{array}{l}\text { Decease in } \mathrm{BP}= \\
13.2 \mathrm{mmHg} \\
15.4 \% \text { decrease in } \\
\mathrm{HR}\end{array}$ & \\
\hline \multirow[t]{3}{*}{$\begin{array}{l}\text { Antileishmanial } \\
\text { activity }\end{array}$} & \multirow[t]{3}{*}{$\begin{array}{l}\text { Whole } \\
\text { plant }\end{array}$} & Methanol extract & \multirow{3}{*}{$\begin{array}{l}\text { MTT assays against } \\
\text { Leishmania infantum } \\
\text { (MHOM/MA/1998/LVTA) } \\
\text { Leishmania tropica } \\
\text { (MHOM/MA/2010/LCTIOK- } \\
\text { 4) } \\
\text { Leishmania major } \\
\text { (MHOM/MA/2009/LCER19- } \\
\text { 09). }\end{array}$} & $\begin{array}{l}\mathrm{IC}_{50}>1000 \text { for } L . \\
\text { major } \\
\mathrm{IC}_{50}=850.76 \text { for } \\
L . \text { tropica } \\
\mathrm{IC}_{50}>1000 \text { for } L . \\
\text { infantum }\end{array}$ & \multirow[t]{3}{*}[22]{} \\
\hline & & Hexane extract & & $\begin{array}{l}\mathrm{IC}_{50}=155.43 \text { for } \\
\text { L. major } \\
\mathrm{IC}_{50}=148.23 \text { for } \\
\text { L. tropica } \\
\mathrm{IC} \mathrm{I}_{50}=14.11 \text { for } L . \\
\text { infantum }\end{array}$ & \\
\hline & & $\begin{array}{l}\text { Dichloromethane } \\
\text { extract }\end{array}$ & & $\begin{array}{l}\mathrm{IC}_{50}=24.56 \text { for } L . \\
\text { major } \\
\mathrm{IC}_{50}=33.77 \text { for } L . \\
\text { tropica } \\
\mathrm{IC}_{50}=31.57 \text { for } L . \\
\text { infantum }\end{array}$ & \\
\hline \multirow[t]{4}{*}{ Antidiabetic effect } & \multirow[t]{4}{*}{$\begin{array}{l}\text { Aerial } \\
\text { parts }\end{array}$} & \multirow[t]{2}{*}{ Methanol extract } & $\alpha$-amylase inhibition activity & $\begin{array}{l}\mathrm{IC}_{50}=101.30 \pm \\
0.08 \mu \mathrm{g} / \mathrm{ml}\end{array}$ & \multirow[t]{4}{*}{ [95] } \\
\hline & & & $\begin{array}{l}\alpha \text {-glucosidase inhibition } \\
\text { activity }\end{array}$ & $\begin{array}{l}\mathrm{IC}_{50}=150.5 \pm 1.40 \\
\mu \mathrm{g} / \mathrm{ml}\end{array}$ & \\
\hline & & \multirow[t]{2}{*}{ Aqueous extract } & $\alpha$-amylase inhibition activity & Non-active & \\
\hline & & & $\begin{array}{l}\alpha \text {-glucosidase inhibition } \\
\text { activity }\end{array}$ & $\mathrm{IC}_{50}>300 \mu \mathrm{g} / \mathrm{ml}$ & \\
\hline $\begin{array}{l}\text { Anti-inflammatory } \\
\text { effect }\end{array}$ & $\begin{array}{l}\text { Aerial } \\
\text { parts }\end{array}$ & $\begin{array}{l}\text { Hydromethanol } \\
\text { extract }\end{array}$ & $\begin{array}{l}\text { Ex vivo membrane } \\
\text { stabilization }\end{array}$ & $\mathrm{IC}_{50}=111 \mu \mathrm{g} / \mathrm{ml}$ & [91] \\
\hline
\end{tabular}




\begin{tabular}{|c|c|c|c|c|c|}
\hline Activities & $\begin{array}{l}\text { Use } \\
\text { part }\end{array}$ & Extracts & Experimental approach & Key results & References \\
\hline & & & $\begin{array}{l}\text { In vivo xylene induced ear } \\
\text { edema }\end{array}$ & $\begin{array}{l}\text { Reduced } 50 \% \text { of } \\
\text { xylene induced ear } \\
\text { edema at } 600 \\
\mathrm{mg} / \mathrm{kg} \text { bw. }\end{array}$ & \\
\hline Larvicidal activity & Stem & $\begin{array}{l}\text { Methyl alcohol } \\
\text { extract }\end{array}$ & $\begin{array}{l}\text { Against fourth larval instar of } \\
\text { Culex quinquefasciatus after } \\
24 \text { h of exposure and maximal } \\
\text { dose } 500 \mathrm{ppm}\end{array}$ & $\begin{array}{l}90.0 \% \text { Mortality } \\
\mathrm{LD}_{50}=311 \\
\mathrm{LD}_{90}>500\end{array}$ & [113] \\
\hline Skin effect & $\begin{array}{l}\text { Aerial } \\
\text { parts }\end{array}$ & $\begin{array}{l}\text { Hexane, Ethyl } \\
\text { acetate, n-butanol } \\
\text { extracts }\end{array}$ & $\begin{array}{l}\text { Acute dermal toxicity test and } \\
\text { Sub-chronic dermal toxicity }\end{array}$ & $\begin{array}{l}\text { not show any toxic } \\
\text { symptoms, } \\
\text { changes in } \\
\text { behaviour or } \\
\text { mortality at the } \\
\text { used dose of } 2000 \\
\text { mg kg }^{-1} \text { b.w. }\end{array}$ & {$[20]$} \\
\hline $\begin{array}{l}\text { Immunomodulatory } \\
\text { activity }\end{array}$ & $\begin{array}{l}\text { Aerial } \\
\text { parts }\end{array}$ & n-BuOH extract & $\begin{array}{l}\text { In vivo phagocytic index using } \\
\text { the carbon clearance rate test }\end{array}$ & $\alpha=0,095 \pm 1,71$ & {$[23]$} \\
\hline \multirow[t]{4}{*}{ Toxicity } & $\begin{array}{l}\text { Aerial } \\
\text { parts }\end{array}$ & $\begin{array}{l}\text { Hexane, Ethyl } \\
\text { acetate, n-butanol } \\
\text { extracts }\end{array}$ & $\begin{array}{l}\text { In vivo acute and subacute oral } \\
\text { toxicity }\end{array}$ & $\begin{array}{l}\text { All extracts with } \\
\text { not cause mice } \\
\text { mortality within } 72 \\
\mathrm{~h} \text { and during the } 14 \\
\mathrm{~d} \text { of observation at } \\
\text { the used dose of } \\
2000 \mathrm{mg} \mathrm{kg}^{-1} \text { b.w. }\end{array}$ & {$[20]$} \\
\hline & Root & Methanol extract & $\begin{array}{l}\text { In vitro on human monocytic } \\
\text { leukemia cells (THP-1) using } \\
\text { MTT assay }\end{array}$ & $\begin{array}{l}70 \% \text { of cell death } \\
\text { at } 1000 \mu \mathrm{g} / \mathrm{mL}\end{array}$ & {$[90]$} \\
\hline & \multirow[t]{2}{*}{$\begin{array}{l}\text { Aerial } \\
\text { parts }\end{array}$} & \multirow[t]{2}{*}{$\begin{array}{l}\text { Hydromethanol } \\
\text { extract }\end{array}$} & $\begin{array}{l}\text { Larvicidal effect on Artemia } \\
\text { salina larvae }\end{array}$ & $\begin{array}{l}\mathrm{LC}_{50}=30 \pm 5.4 \\
\mu \mathrm{g} / \mathrm{mL}\end{array}$ & \multirow[t]{2}{*}{ [91] } \\
\hline & & & $\begin{array}{l}\text { In vivo acute and subacute oral } \\
\text { toxicity }\end{array}$ & $\begin{array}{l}\text { Did not exhibit any } \\
\text { acute/subacute } \\
\text { toxicity effect on } \\
\text { mice. }\end{array}$ & \\
\hline \multirow[t]{4}{*}{$\begin{array}{l}\text { Xanthine oxidase } \\
\text { activity }\end{array}$} & & $\begin{array}{l}\text { Chloroform } \\
\text { extract }\end{array}$ & \multirow[t]{4}{*}{ Colorimetric method } & $\begin{array}{l}\mathrm{IC}_{50}=0.0088 \pm \\
0.000 \mathrm{mg} / \mathrm{mL}\end{array}$ & \multirow[t]{4}{*}[21]{} \\
\hline & & Crud extract & & $\begin{array}{l}\mathrm{IC}_{50}=0.0520 \pm \\
0.0030 \mathrm{mg} / \mathrm{mL}\end{array}$ & \\
\hline & & $\begin{array}{l}\text { Ethyl acetate } \\
\text { extract }\end{array}$ & & $\begin{array}{l}\mathrm{IC}_{50}=0.0165 \pm \\
0.0010 \mathrm{mg} / \mathrm{mL}\end{array}$ & \\
\hline & & Aqueous extract & & $\begin{array}{l}\mathrm{IC}_{50}=0.9800 \pm \\
0.0040 \mathrm{mg} / \mathrm{mL}\end{array}$ & \\
\hline
\end{tabular}

3.5.15. Other properties.

In addition to their pharmacological effects, several authors reported different investigations of $S$. verbenaca, including preventing self-fertilization, fruit and seeds production, production of phytomass, soil adaptation, a correlation between the classical taxonomy and chemical taxonomy, phytoremediation, insecticide agent, and allelopathic effects on plant development.

Navarro and collaborators investigated the dichogamy of S. verbenaca for preventing self-fertilization based on the quantification of temporal variability in pollen germinability and the length of the period of stigma receptivity. From this study, the authors reported that the occurrence or non-occurrence of selfing in protandrous species was more dependent on pollen germination patterns than the temporal separation of the stamen dehiscence and stylar elongation phases [114]. One year later, the same authors investigated the cause of variation in fruit and seed production of this plant and reported that neither fruit set nor seed/ovule ratio varied significantly among inflorescences [115]. These findings suggested that the pattern of inflorescence variation in mean single-seed weight was attributed to a gradual increase in the non-self-pollen receipt as the flowering season progressed. 
In 2002, Castro et al. (2002) studied the use of $S$. verbenaca in urban green spaces after their seed broadcast at the following densities: 20 000, 15000,10000 , and 5000 viable seeds $/ \mathrm{m}^{2}$. The result showed that between 5000 and $10000 \mathrm{~m}^{2}$, the densities of seeding could be more advantageous [116].

To identify their landscape potential in low-maintenance conditions, Bretzel and coworkers (2009) evaluated the ecological characteristics and the cultivation needs of $S$. verbenaca and found that the plant height of $S$. verbenaca was not affected by soil characteristics $(68 \mathrm{~cm}$ in non-cultivated soil vs.78 cm in soil from the mixture of a noncultivated and regularly fertilized soil) [117]. In addition, this plant showed a higher production of biomass in non-cultivated soil (172 $\mathrm{g} \mathrm{DM} / \mathrm{m})$ compared with the mixture soil $(149 \mathrm{~g} \mathrm{DM} / \mathrm{m})$, suggesting their adaptation to infertile soils. In another study, Fisheretal et al. (2016) investigated the efficacy conditions for seed germination of three-month-old and nine years old seeds of $S$. verbenaca and showed that germination of the three-month-old seed was significantly less than nine-year-old seed (41\% vs. $7.4 \%$, respectively) [118]. Recently, the optimum conditions for germination of two varieties of $S$. verbenaca ( $S$. verbenaca var. verbenaca and $S$. verbenaca var. vernalis) were conducted by Javaid and coworkers (2018) [119]. The result showed that both varieties germinated strongly at neutral $\mathrm{pH}$. Their germination rate was significantly inhibited by complete darkness. In contrast, $S$. verbenaca var. vernalis showed slightly more tolerance to reduced moisture availability, moderate to strong salinity, and burial depth, compared to $S$. verbenaca var. verbenaca.

Furthermore, the correlation between the classical taxonomy and chemical taxonomy in Salvia sp. L. was conducted by Naküboúlu (2002) [120]. The coefficient of similarity and the matching coefficient of $S$. verbenaca and $S$. virgate reported a value of 0.66 and 0.87 , respectively, which showed clearly the degrees of these species' relativity. The authors of this study suggested that chemotaxonomy can be used in the taxonomy of Salvia species. In addition, Ifrim investigated the differences in ornamentation and mucilage production in Salvia nutlets and reported that seeds of $S$. verbenaca presented a reticulate surface and produced mucilage when they are in contact with water [121]. The authors suggested that the surface of the nutlets in Salvia highlights characters that may be used to clarify some taxonomic aspects at the species level.

The potential of Salvia verbenaca for phytoremediation of trace metals from soil contaminated with copper mine tailings treated with technosol and compost was conducted by Novo and coworkers (2013) [122]. Salvia verbenaca had the ability to tolerate trace metals and effectively respond to the subsequent oxidative stress towards $\mathrm{Cd}$.

In 2014, Fatiha et al. (2014) tested the insecticide effect of $S$. verbenaca essential oil in vitro (at 10, 20, and $30 \mu \mathrm{l}$ ) on different biological parameters of Callosobruchus chinensis $\mathrm{L}$. such as fertility, longevity, and fecundity, under controlled temperature and relative humidity $\left(28^{\circ} \mathrm{C}\right.$ and $\left.75 \%\right)$ [123]. The essential oil did not affect Cicer arietinum L. germination, while at $30 \mu \mathrm{l}$, it caused a significant reduction in longevity (2.8, and 4.6 days for males and females, respectively) and inhibition of oviposition ( $0 \%$ compared with $39.8 \%$ in the control group).

Another study reported the allelopathic effects of the essential oils of S. verbenaca on plant development [118]. The authors tested the allelopathic effect of $S$. verbenaca essential oils in vitro on the germination of $L$. sativa. The results showed that essential oil had a strong inhibitory effect $(1.00 \pm 0.50 \mathrm{~mm})$ on radical growth compared with those treated with the leachate $(1.29 \pm 0.27 \mathrm{~mm})[118]$. 


\section{Conclusions and Future Perspective}

This bibliometric survey reported a review of $S$. verbenaca regarding their ethnomedicinal use, geographic distribution, taxonomy, bioactive compounds, pharmacological activities, and toxicological evidence. The phytochemical analysis conducted by several research groups showed that this plant contains different bioactive compounds, especially terpenoids in the essential oils of this plant. Terpenoids were dominated by hexadecanoic acid, $\beta$-phellandrene, $\beta$-caryophyllene, camphor, sabinene, germacrene $D$. Its flavonoids and phenolic acids were naringenin, and rosmarinic acid as the main compounds, respectively. However, there is a lack of research on flavonoids and phenolic acids in flowers, seeds, roots, and fruits. Thus, investigation of these chemical classes in these parts should be explored using different analytical tools such as HPLC, GC-MS, and LC-MS. Furthermore, in vitro and in vivo pharmacological effects of $S$. verbenaca extracts and essential oils possessed several biological effects, including antioxidant, antidiabetic, antibacterial, antifungal, antitumor, antihemolytic, antihypertensive, antileishmanial, and immunomodulatory activities. However, elaborating the pharmacokinetic and pharmacodynamic studies is necessary to prove these compounds' molecular effects on human health. Moreover, little literature data are available on the toxicological of $S$. verbenaca. Therefore, to determine the safety of this plant, further toxicological studies are necessary.

\section{Funding}

This research received no external funding.

\section{Acknowledgments}

This research has no acknowledgment.

\section{Conflicts of Interest}

The authors declare no conflict of interest.

\section{References}

1. Ben Farhat, M.; Landoulsi, A.; Chaouch-Hamada, R.; Sotomayor, J.A.; Jordánc, M.J. Phytochemical composition and in vitro antioxidant activity ofby-products of Salvia verbenaca L. growing wild in different habitats. Ind Corps Prod 2013, 49, 373-379,_http://dx.doi.org/10.1016/j.indcrop.2013.05.006.

2. Al-Jaber, H.I.; Obeidat, S.M.; Afifi, F.U.; Abu Zarga, M.H.. Aroma Profile of Two Populations of Salvia verbenaca Collected from Two Bio-Geographical Zones from Jordan. Chem Biodivers 2020, 17, https://doi.org/10.1002/cbdv.201900553.

3. Codd Leslie E., Leistner O.A. Flora of Southern Africa. 28, Part 4, Lamiaceae. Pretoria: Botanical Research Institute, Department of Agricultural and Water Supply, 1985. Print.

4. Ahmed, B.; Al-Howiriny, T.A.; Mose, J.S.; Tahir, K.E.H.EL. Isolation, antihypertensive activity and structure activity relationship of flavonoids from three medicinal plants. Indian J Chem 2005, 44B, 400-404.

5. Walker, J. B.; Sytsma, K.J.; Treutlein, J.; Wink, M. Salvia (Lamiaceae) is not monophyletic: implications for the systematics, radiation, and ecological specializations of Salvia and tribe Mentheae. Am J Bot 2004, 91, 1115-1125, https://doi.org/10.3732/ajb.91.7.1115.

6. Guarrera, P.M.; Forti, G.; Marignoli, S. Ethnobotanical and ethnomedicinal uses of plants in the district of Acquapendente (Latium, Central Italy). J Ethnopharmacol 2005, 96, 429-444, https://doi.org/10.1016/j.jep.2004.09.014. 
7. González, J.A.; García-Barriuso, M.; Amich, F. Ethnobotanical study of medicinal plants traditionally used in the Arribes del Duero, western Spain. $J$ Ethnopharmacol 2010, 131, 343-355, https://doi.org/10.1016/j.jep.2010.07.022.

8. Bouayyadi, L.; El Hafian, M.; Zidane, L. Étude floristique et ethnobotanique de la flore médicinale dans la région du Gharb, Maroc. J Appl Biosci 2015, 93, 8760-8769.

9. Lahsissene, H.; Kahouadji, A.; Tijane, M.; Hseini, S. Catalogue des plantes médicinales utilisées dans la region de Zaër (Maroc Occidental). Lejeunia 2009.

10. Chermat, S.; Gharzouli, R. Ethnobotanical Study of Medicinal Flora in the North East of Algeria-An Empirical Knowledge in Djebel Zdimm (Setif). JMSE 2015, https://doi.org/10.17265/2161-6213/2015.12.007.

11. Salhi, S.; Fadli, M.; Zidane, L.; Douira, A. Etudes floristique et ethnobotanique des plantes médicinales de la ville de Kénitra (Maroc). Lazaroa 2010, 31,133-146, https://doi.org/10.5209/rev_LAZA.2010.v31.9.

12. Yabrir, B.; Touati, M.; Adli, B.; Bezini, E.; Ghafoul, M.; Khalifa, S.; Guit, B. Therapeutic use of spontaneous medicinal flora from an extreme environment (dune cordon) in Djelfa region, Algeria. J Pharm Pharmacogn Res 2018, 6,358-373.

13. Akdime, H.; Boukhira, S.; El Mansouri, L.; Hamsas El Youbi, A.; Bousta, D. Ethnobotanical Study and Traditional Knowledge of Medicinal Plants in Ain Leuh Region (Middle-Atlas of Morocco). Am J Adv Drug Deliv 2015, 3, 248-263.

14. Cornara, L.; La Rocca, A.; Marsili, S.; Mariotti, M.G. Traditional uses of plants in the Eastern Riviera (Liguria, Italy). J Ethnopharmacol 2009, 125, 16-30, https://doi.org/10.1016/j.jep.2009.06.021.

15. Gras, A.; Serrasolses, G.; Vallès, J.; Garnatje, T. Traditional knowledge in semi-rural close to industrial areas: Ethnobotanical studies in western Gironès (Catalonia, Iberian Peninsula). J Ethnobiol Ethnomedicine 2019, https://doi.org/10.1186/s13002-019-0295-2.

16. Hendel, N.; Larous, L.; Sari, M.; Boudjelal, A.; Sarri, D. Place of Labiates in folk medicine of the area of M'sila (Algeria). Glob J Res Med Plants Indig Med 2012, 1, 315.

17. Martínez-Francés, V.; Hahn, E.; Juan-Vicedo, J.; Vila, R.; Ríos, S.; Cañigueral S. Ethnobotanical study of the sages used in traditional Valencian medicine and as essential oil: Characterization of an endemic Salvia and its contribution to local development. Contrib Sci 2012, 8, 77-84, https://doi.org/10.2436/20.7010.01.137.

18. Sarac, N.; Uğur, A. Antimicrobial activities and usage in folkloric medicine of some Lamiaceae species growing in Mugla, Turkey. Eurasia J Biosci 2007, 1, 28-37.

19. Canzoneri, M.; Bruno, M.; Rosselli, S.; Russo, A.; Cardile, V.; Formisano, C.; Rigano, D.; Senatore, F. Chemical composition and biological activity of Salvia verbenaca essential oil. Nat Prod Commun 2011, 6, 1023-1026.

20. Guaouguaou, F.Z.; Taghzouti, K.; Oukabli, M.; Masrar, A.; Chabraoui, L.; Bouabdellah, M.; Es-Safi, N.D. Acute and Subchronic Oral and Dermal Toxicological Studies of Salvia verbenaca Extracts in Mice and Rats. J Herbs Spices Med Plants 2018, https://doi.org/10.1080/10496475.2018.1556372.

21. Belkhiri, F.; Baghiani, A.; Zerroug, M.M.; Arrar, L. Investigation of antihemolytic, xanthine oxidase inhibition, antioxidant and antimicrobial properties of Salvia verbenaca L. aerial part extracts. Afr $J$ Tradit Complement Altern Med 2017, 14, 273-281, https://doi.org/10.21010/ajtcam.v14i2.29.

22. Et-Touys, A.; Fellah, H.; Sebti, F.; Mniouil, M.; Aneb, M.; El-Boury, H.; Talbaoui, A.; Dakka, N.; Sadak, A.; Bakri, Y. In vitro Antileishmanial Activity of Extracts from Endemic Moroccan Medicinal Plant Salvia verbenaca (L.) Briq. ssp verbenaca Maire (S. clandestina Batt. non L). European Journal of Medicinal Plants 2016, 16, 1-8.

23. Nassar, M.; Zerizer, S.; Kabouche, Z.; Kabouche, A.; Bechkri, S. Antioxidant and the immunomodulatory activities exhibited by three plants from Lamiaceae family. Int J Pharm Pharm Sci 2015, 7, 331-334.

24. Ben Farhat, M.; Sotomayor, J.A.; Jordan, M.J. Salvia verbenaca L. Essential oil: Variation of yield and composition according to collection site and phenophase. Biochem Syst Ecol 2019, 82, 35-43, https://doi.org/10.1016/j.bse.2018.12.002.

25. Ben Farhat, M.; Chaouch-Hamada, R.; Sotomayor, J.A.; Landoulsi, A.; Jordán, M.J. Antioxidant properties and evaluation of phytochemical composition of Salvia verbenaca L. extracts at different developmental stages. Plant Foods Hum Nutr 2015,70, 15-20, https://doi.org/10.1007/s11130-015-0466-9.

26. Al-Howiriny, T.A. Chemical composition and antimicrobial activity of essential oil of S. verbenaca. Biotec 2002, 1, 45-48. 
27. Russo, A.; Cardile, V.; Graziano, A.C.; Formisano , C.; Rigano , D.; Canzoneri, M.; Bruno, M.; Senatore, F. Comparison of essential oil components and in vitro anticancer activity in wild and cultivated Salvia verbenaca. Nat Prod Res 2015, 29, 1630-1640, https://doi.org/10.1080/14786419.2014.994212.

28. Hu, G.X.; Peng, H. Identity of Salvia weihaiensis (Lamiaceae) from China. Phytotaxa 2015, 202, 298-300, http://dx.doi.org/10.11646/phytotaxa.202.4.10.

29. Navarro, L. Is the dichogamy of Salvia verbenaca (Lamiaceae) an effective barrier to self-fertilization? $P l$ Syst Evol 1997, 207, 111-117, https://doi.org/10.1007/BF00985212.

30. Bojnanský, V.; Fargašová, A. Atlas of Seeds and Fruits of Central and East-European Flora. Springer, 2007.

31. Petanidou, T.; Vokou, D. Pollination ecology of Labiatae in a phryganic (East Mediterranean) ecosystem. Amer J Bot 1993, 80, 892-899.

32. Ranjbar, M.; Pakatchi, A.; Babataheri, Z. Chromosome number evolution, biogeography and phylogenetic relationships in Salvia (Lamiaceae). Webbia 2015, https://doi.org/10.1080/00837792.2015.1057982.

33. O’Leary, N.; Moroni, P. Las especies de Salvia (Lamiaceae) para Argentina. Darwiniana, Nueva Serie 2016, 4, 91-131, https://doi.org/10.14522/darwiniana.2016.41.694.

34. Afzal-Rafii, Z. Contribution to the cytotaxonomic study of the Salvia verbenaca L group. Bulletin of the Botanical Society of France (Botanical Letters) 1979, 126, 79-86, https://doi.org/10.1080/01811797.1979.10824377.

35. Hedge, I.C. Salvia. In: Davis, P.H., ed. Flora of Turkey and the East Aegean Islands. Vol. 7. Edinburgh: Edinburgh University Press, 1982, 400-461.

36. Esra, M.; Cetin, O.; Kahraman, A.; Celep, F.; Dogan, M. A cytomorphological study in some taxa of the $\begin{array}{lllll}\text { genus Salvia L } & \text { (Lamiaceae). }\end{array}$ https://doi.org/10.1080/00087114.2011.10589793.

37. Hedge, I.C. A revision of Salvia in Africa, including Madagascar and the Canary Islands. Notes Roy Bot Gard Edinburgh 1974, 33, 1-121.

38. Tahri, N.; El Basti, A.; Zidane, L.; Rochdi, A.; Douira, A. Etude ethnobotanique des plantes medicinales dans la province de Settat (Maroc). Kastamonu Üni Orman Fakültesi Dergisi 2012, 12, 192-208.

39. Moussi, I.M.; Filali, H.; Tazi, A.; Hakkou, F. Ethnobotanical survey of healing medicinal plants traditionally used in the main Moroccan cities. JPP 2015, 7, 164-182, https://doi.org/10.5897/JPP2015.0355.

40. Abbouyi, P.A.; Ansari, N.F.; Khyari, P.S.; Loukili, H. Inventory of medicinal plants prescribed by traditional healers in El Jadida city and suburbs (Morocco). Int J Green Pharm 2014, 8, 242.

41. Cavero, R.Y.; Akerreta, S.; Calvo, M.I. Medicinal plants used for dermatological affections in Navarra and their pharmacological validation. $J \quad$ Ethnopharmacol 2013, 149, 533-542, https://doi.org/10.1016/j.jep.2013.07.012.

42. Nassiri, L.; Zarkani1, S.; Daoudi1, A.; Bammou, M.; Bouiamrine1, H.; Ibijbijen, J. Contribution to the establishment of ethno botanical catalog of Aguelmous (Khenifra, Morocco). IJIAS 2016, 17, 373-387.

43. Sanna, C.; Ballero, M.; Maxia, A. Le piante medicinali utilizzate contro le patologie epidermiche in ogliastra (Sardegna Centro-Orientale). Atti Soc tosc Sci nat Mem Serie B 2006, 113, 73-82.

44. Salhi, N.; Bouyahya, A.; Fettach, S.; Zellou, A.; Cherrah, Y. Ethnopharmacological study of medicinal plants used in the treatment of skin burns in occidental Morocco (area of Rabat). S Afr J Bot 2019, 121, 128-142, https://doi.org/10.1016/j.sajb.2018.10.038.

45. Demirci, S.; Özhatay, N. An ethnobotanical study in kahramanmaras (Turkey) wild plants used for medicinal purpose in andirin, kahramanmaras. Turk J Pharm Sci 2012, 9, 75-92.

46. Gonzalez, J.A.; Barriuso, M.G.; Rodriguez, R.R.; Bernardos, S.; Amich, F. Ethnobotanical Resources Management in the Arribes del Duero Natural Park (Central Western Iberian Peninsula): Relationships between Plant Use and Plant Diversity, Ecological Analysis, and Conservation. Hum Ecol 2013, 41, 615-630. https://doi.org/10.1007/s10745-013-9603-y.

47. Sari, M.; Hendel, N.; Sarri, D.; Boudjelal, A.; Benkhaled, A. Ethnobotanical study of medicinal flora used by the people of the forest of El Haourane-M'Sila-(Algeria). Journal of Eco Agri Tourism 2013, 9, 21-25.

48. Nath, E.Ö.; Kültür, Ş. The local names of the plants in Kepsut and Savaştepe (Balıkesir, Turkey). Istanbul J Pharm 2017, 47,13-24, https://doi.org/10.5152/IstanbulJPharm.2017.004.

49. Benkhnigue, O.; Zidane, L.; Fadli, M.; Elyacoubi, H.; Rochdi, A.; Douira, A. Ethnobotanical study of medicinal plants in the region of Mechraâ Bel Ksiri (Gharb region of Morocco). Acta Bot Barc 2011, 53, 191216. 
50. Oran, S. Flora of Bader Al-Jadida County, Western high mountains of Amman city/Jordan. Int J Herbs Med 2015, 3, 49-59, http://dx.doi.org/10.22271/flora.

51. Palaci, J.; Belda, A.; Belda, I.; Larrosa, J. A. Construction of a GIS of the medicinal plants of the Sierra de Mariola: an application of the ATC System. Espagrafic ed.; Mediterranean: Biological Studies Series Epoch II, Spain, 2010; 9-39.

52. John, H.; Böhme, F. Salbei- Arten, die noch nicht im Rothmaler stehen. Mitt. florist. Kart. Sachsen-Anhalt 2007, 12, 83-86.

53. Benítez, G.; González-Tejero, M. R.; Molero-Mesa, J. Pharmaceutical ethnobotany in the western part of Granada province (southern Spain): ethnopharmacological synthesis. J ethnopharmacol 2010, 129, 87-105, https://doi.org/10.1016/j.jep.2010.02.016.

54. Botella, JV; Mateo Sanz, G. Referencias etnobotánicas en la obra de Clemente "Historia civil, natural y eclesiástica de Titaguas". Flora Montiberica 2014, 57, 24-30.

55. Ennabili, A.; Gharnit, N.; El Hamdouni, EM. Inventory and social interest of medicinal, aromatic and honeyplants from mokrisset region (NW of Morocco). Stud Bot 2000, 19, 57-74.

56. Guarrera P.M. Traditional phytotherapy in Central Italy (Marche, Abruzzo, and Latium). Fitoterapia 2005, 76, 1-25, https://doi.org/10.1016/j.fitote.2004.09.006.

57. Latif, A.; Amer, H.M.; Hamad, M.E.; Alarifi, S.A.R.; Almajhdi, F.N. Medicinal plants from Saudi Arabia and Indonesia: In vitro cytotoxicity evaluation on Vero and HEp-2 cells. J Med Plants Res 2014, 8, 10651073, https://doi.org/10.5897/JMPR2014.5481.

58. Rigat, M.; Vallès, J.; D'Ambrosio, U.; Gras, A.; Iglésias, J.; Garnatje, T. Plants with topical uses in the Ripollès district (Pyrenees, Catalonia, Iberian Peninsula): ethnobotanical survey and pharmacological validation in the literature. J Ethnopharmacol 2015, 164, 162-179, https://doi.org/10.1016/j.jep.2015.01.055.

59. Ozturk, M.; Altundag, E.; Gucel, S. Medicinal and aromatic plants (Turkey). In Ethnopharmacology, Encyclopedia of Life Support Systems (EOLSS), 2012.

60. Ben Taarit, M.; Msaada, K.; Hosni, K.; Ben Amor, N.; Marzouk, B.; Kchouk, M.E. Chemical Composition of the Essential Oils Obtained from the Leaves, Fruits and Stems of Salvia verbenaca L. from the Northeast Region of Tunisia. J Ess Oil Res 2010, 22, 449-453, https://doi.org/10.1080/10412905.2010.9700369.

61. Al-Jaber, H.I.; Obeidat, S.M.; Afifi, F.U.; Abu Zarga, M.H. Aroma profile of two populations of Salvia verbenaca collected from two bio-geographical zones from Jordan. Chem. Biodiversity 2020, 17, e1900553, https://doi.org/10.1002/cbdv.201900553.

62. Ben Taarit, M.; Msaada, K.; Hosni, K.; Marzouk, B. Chemical composition of fatty acids and essential oils of Salvia verbenaca L. Seeds from Tunisia. Agrochimica 2010, 54, 129-141.

63. Ben Taârit, M.; Msaada, K.; Hosni, K.; Marzouk, B. GC Analyses of Salvia seeds as valuable essential oil source. Advances in Chemistry 2014, https://doi.org/10.1155/2014/838162.

64. Pitarokili, D.; Tzakou, O.; Loukis, A. Essential oil composition of Salvia verticillata, S. verbenaca, S. glutinosa and S. candidissima growing wild in Greece. Flavour Fragr J 2006, 21, 670-673, https://doi.org/10.1002/ffj.1647.

65. Ahmed, B.; Al-Howiriny, T.A.; Al-Rehaily, A.J.; Mossa, J.S. Verbenacine and salvinine: two new diterpenes from Salvia verbenaca. Zeitschrift fur Naturforschung C 2004, 59, 9-14, https://doi.org/10.1515/znc-2004$1-202$.

66. Khemkham, A.; Belhadj, S.; Meddour, R.; Kenmoku, H.; Aissaoui, R.; Gourine, N.; Yousfi, M.; Hakem, A.; Asakawa, Y. HS-SPME-GC/MS analysis of 3 Lamiaceae plants: Ajuga iva (1.) Schreb., Salvia verbenaca L. and Thymus algeriensis Boiss. \& Reut. J Fund Appl Sci 2020, 12, 700-711, https://doi.org/https://doi.org/10.4314/jfas.v12i2.12.

67. Sabri, N.N.; Abou-Donia, A.A.; Assad, A.M.; Ghazy, N.M.; El-Lakany, A.M.; Tempesta, M.S.; Sanson, D.R. Abietane diterpene Quinones from the roots of Salvia verbenaca and S. lanigera. Planta Med 1989, 55, 582, https://doi.org/10.1055/s-2006-962111.

68. Mannu, A.; Melito, S.; Petretto, G.L.; Manconi, P.; Pintore, G.M.; Chessa, M. Geographical variation of the chemical composition in essential oils extracted from Sardinian Salvia verbenaca. Nat Prod Res 2020, https://doi.org/10.1080/14786419.2020.1788021.

69. Ben Taarit, M.; Msaada, K.; Hosni, K.; Chahed, T.; Marzouk, B. Essential oil composition of Salvia verbenaca L. growing wild in Tunisia. J Food Biochem 2010, 30, 142-151, https://doi.org/10.1111/j.17454514.2009.00270.x. 
70. Aissaoui, M.; Chalard, P.; Figuérédo, G.; Marchioni, E.; Zao, M.; Benayache, F.; Benayache, S. Chemical composition of the essential oil of Salvia verbenaca (L.) Briq. ssp. pseudo-jaminiana (Chev.) M. RJPBCS 2014, 5, 368-372.

71. Belloum, Z.; Chalard, P.; Figuérédo, G.; Marchioni, E.; Zao, M.; Benayache, F.; Benayache, S. Chemical composition of the essential oil of Salvia verbenaca (L.) Briq. ssp clandestina (L.) Pugsl. RJPBCS 2014, 5, 262-265.

72. Al-Jaber, H.I. Essential oil composition of the aerial parts of Fresh and Airdried Salvia verbenaca L. growing wild in Jordan. J Essent Oil-Bear Plants 2015, 18, 718-724, https://doi.org/10.1080/22311866.2014.983976.

73. Camarasa, J.; Canigueral, S.; Iglesias, J.; Marin, E. The flavonic aglycons of leaves of Salvia verbenaca L. leaves: 5-hydroxy 7,4'-dimethoxy flavone, new flavenoid for Salvia L. genus. Plantes Médicinales et Phytothérapie 1982, 3, 192-196.

74. Ben Farhat, M.; Chaouch-Hamada, R.; Landoulsi, A. Oil yield and fatty acid profile of seeds of three Salvia species. A comparative study. Herba Pol 2015, 62, 14-29, https://doi.org/10.1515/hepo-2015-0012.

75. Salah, K.B.H.; Mahjoub, M.A.; Ammar, S.; Michel, L.; Millet-Clerc, J.; Chaumont, J.P.; Mighri, Z.; Aouni, M. Antimicrobial and antioxidant activities of the methanolic extracts of three Salvia species from Tunisia. Nat Prod Res 2006, 20, 1110-1120, https://doi.org/10.1080/14786410600834230.

76. Kamatou, G.P.P.; Van Vuuren, S.F.; Van Heerden, F.R.; Seaman, T.; Viljoen, A.M. Antibacterial and antimycobacterial activities of South African Salvia species and isolated compounds from S. chamelaeagnea. S Afr J Bot 2007, 73, 552-557, https://doi.org/10.1016/j.sajb.2007.05.001.

77. Sarac, N; Ugur, A. Antimicrobial activities and usage in folkloric medicine of some Lamiaceae species growing in Mugla, Turkey. EurAsia J BioSci 2007, 4, 28-37.

78. Al-Zereini, W.A. Ononis natrix and Salvia verbenaca: Two Jordanian medicinal plants with cytotoxic and antibacterial activities. J Herbs Spices Med Plants 2017, 23, 18-25, https://doi.org/10.1080/10496475.2016.1241200.

79. Kabouche, A.; Kabouche, Z. Bioactive diterpenoids of Salvia species. Stud Nat Prod Chem 2008, 35, 753833, https://doi.org/10.1016/S1572-5995(08)80017-8.

80. Bouyahya, A.; Bakri, Y.; Et-Touys, A.; Talbaoui, A.; Khouchlaa, A.; Charfi, S.; Abrini, J.; Dakka, N. Resistance to antibiotics and mechanisms of action of essential oils against bacteria. Phytothérapie 2017, https://doi.org/10.1007/s10298-017-1118-z.

81. Song, H.S.; Bhatia, S.K.; Gurav, R.; Choi, T.R.; Kim, H.J.; Park, Y.L.; Han, Y.H.; Park, J.Y.; Lee, S.M.; Park, S.L.; Lee, H.S.; Kim, W.; Kim, Y.G.; Yang, Y.H. Naringenin as an antibacterial reagent controlling of biofilm formation and fatty acid metabolism in MRSA. bioRxiv 2020, https://doi.org/10.1101/2020.03.08.983049.

82. Bouyahya, A.; Belmehdi, O.; El Jemli, M.; Marmouzi, I.; Bourais, I.; Abrini, J.; Faouzi, M.E.A.; Dakka, N.; Bakri, Y. Chemical variability of Centaurium erythraea essential oils at three developmental stages and investigation of their in vitro antioxidant, antidiabetic, dermatoprotective and antibacterial activities. Ind Crop Prod 2019, 132, 111-117, https://doi.org/10.1016/j.indcrop.2019.01.042.

83. Bouyahya, A.; Chamkhi, I.; Guaouguaou, F.Z.; Benali, T.; Balahbib, A.; El Omari, N.; Taha, D.; El-Shazly, M.; El Menyiy, N. Ethnomedicinal use, phytochemistry, pharmacology, and food benefits of Thymus capitatus. J Ethnopharmacol 2020, 112925, https://doi.org/10.1016/j.jep.2020.112925.

84. Bonesi, M.; Loizzo, M.R.; Acquaviva, R.; Malfa, G.A.; Aiello, F.; Tundis, R. Anti-inflammatory and antioxidant agents from Salvia genus (Lamiaceae): An assessment of the current state of knowledge. Antiinflamm Antiallergy Agents Med Chem 2017, 16, 70-86, https://doi.org/10.2174/1871523016666170502121419.

84. Lu, Y.; Yeap Foo, L. Polyphenolics of Salvia-a review. Phytochemistry 2002, 59, 117-140, https://doi.org/10.1016/S0031-9422(01)00415-0.

86. Khlifi, S.; El Hachimi, Y.; Khalil, A.; Es-Safi, N.; Belahyan, A.; Tellal, R.; El Abbouyi, A. In vitro antioxidant properties of Salvia verbenaca L. hydromethanolic extract. Indian J Pharmacol 2006, 38, 276-280, https://doi.org/ 10.4103/0253-7613.27025.

87. Tepe, B. Antioxidant potentials and rosmarinic acid levels of the methanolic extracts of S. virgata (Jacq), $S$. staminea (Montbret \& Aucher ex Bentham) and S. verbenaca (L.) from Turkey. Bioresour Technol 2008, 99 , 1584-1588, https://doi.org/10.1016/j.biortech.2007.04.008.

88. Ben Farhat, M.B.; Landoulsi, A.; Chaouch-Hamada, R.; Sotomayor, J.A.; Jordán, M.J. Characterization and quantification of phenolic compounds and antioxidant properties of Salvia species growing in different habitats. Ind Crop Prod 2013, 49, 904-914, https://doi.org/10.1016/j.indcrop.2013.06.047. 
89. Šulniūtè, V.; Ragažinskienè, O; Venskutonis, P.R. Comprehensive evaluation of antioxidant potential of 10 Salvia species using high pressure methods for the isolation of lipophilic and hydrophilic plant fractions. Plant Foods Hum Nutr 2016, 71, 64-71, https://doi.org/10.1007/s11130-015-0526-1.

90. Nassar, M.; Zadri, F.; Slimani, S. Assessment of the protective effect of the methnolic extract from Salvia verbenaca roots against oxidative damage induced by hydrogen peroxide $\left(\mathrm{H}_{2} \mathrm{O}_{2}\right)$. Turk J Pharm Sci 2020, https://doi.org/10.4274/tjps.galenos.2020.74555.

91. Righi, N.; Boumerfeg, S.; Deghima, A.; Fernandes, P.; Coelho, E.; Baali, F.; Cardoso, S. M.; Coimbra, M. A.; Baghiani, A. Phenolic profile, safety assessment, and anti-inflammatory activity of Salvia verbenaca L. J Ethnopharmacol 2021, 272, 113940, https://doi.org/10.1016/j.jep.2021.113940.

92. Zhao, J.; Lou, J.; Mou, Y.; Li, P.; Wu, J.; Zhou, L. Diterpenoid tanshinones and phenolic acids from cultured hairy roots of S. miltiorrhiza Bunge and their antimicrobial activities. Molecules 2011, 16, 2259-2267, https://doi.org/10.3390/molecules16032259.

93. Fettach, S.; Mrabti, H.N.; Sayah, K.; Bouyahya, A.; Salhi, N.; Cherrah, Y.; El Abbes, F. Phenolic content, acute toxicity of Ajuga iva extracts and assessment of their antioxidant and carbohydrate digestive enzyme inhibitory effects. S Afr J Bot 2019, 125, 381-385, https://doi.org/10.1016/j.sajb.2019.08.010.

94. Bouyahya, A.; Dakka, N.; Talbaoui, A.; Et-Touys, A.; El-Boury, H.; Abrini, J.; Bakri, Y. Correlation between phenological changes, chemical composition and biological activities of the essential oil from Moroccan endemic Oregano (Origanum compactum Benth). Ind Crop Prod 2017, 108, 729-737, https://doi.org/10.1016/j.indcrop.2017.07.033.

95. Mamache, W.; Amira, S.; Ben Souici, C.; Laouer, H.; Benchikh, F. In vitro antioxidant, anticholinesterases, anti- $\alpha$-amylase, and anti- $\alpha$-glucosidase effects of Algerian Salvia aegyptiaca and Salvia verbenaca. J Food Biochem 2020, 44, e13472, https://doi.org/10.1111/jfbc.13472.

96. Badisa, R.B., Tzakou, O., Couladis, M., Pilarinou, E. Cytotoxic activities of Salvia of the Labiatae family. Pharm Biol 2005, 42, 640-645, https://doi.org/10.1080/13880200490902590.

97. Latif, A.; Amer, H.M.; Hamad, M.E.; Rahaman Alarifi, S.A., Fahad Nasser Almajhdi, F.N. Medicinal plants from Saudi Arabia and Indonesia: In vitro cytotoxicity evaluation on Vero and HEp-2 cells. J Med Plants Res 2014, 8, 1065-1073, https://doi.org/10.5897/JMPR2014.5481.

98. Pakdemirli, A.; Karaca, C.; Sever, T.; Daşkin, E.; Leblebici, A.; Yiğitbaşi, T.; Başbinar, Y. Carvacrol alters soluble factors in HCT-116 and HT-29 cell lines. Turk J Med Sci 2020,50, 271-276, https://doi.org/10.3906/sag-1907-173.

99. Mari, A.; Mani, G.; Nagabhishek, S. N.; Balaraman, G.; Subramanian, N.; Mirza, F.B.; Sundaram, J.; Thiruvengadam, D. Carvacrol promotes cell cycle arrest and apoptosis through PI3K/AKT signaling pathway in MCF-7 breast cancer cells. Chin J Integr Med 2020, https://doi.org/10.1007/s11655-020-3193-5.

100.Andrade-Narváez, F.J.; Vargas-González, A.; Canto-Lara, S.B.; Damián-Centeno, A.G. Clinical picture of cutaneous leishmaniases due to Leishmania (Leishmania) mexicana in the Yucatan peninsula, Mexico. Mem Inst Oswaldo Cruz 2001, 96, 163-167, https://doi.org/10.1590/s0074-02762001000200005.

101.Roatt, B.M.; de Oliveira Cardoso, J.M.; De Brito, R.C.F.; Coura-Vital, W.; Aguiar-Soares, R.D.O.; Reis, A.B. Recent advances and new strategies on leishmaniasis treatment. Appl Microbiol Biotechnol 2020, 104, 8965-8977, https://doi.org/10.1007/s00253-020-10856-w.

102.Singh, N.; Mishra, B.B.; Bajpai, S.; Singh, R.K.; Tiwari, V.K. Natural product based leads to fight against leishmaniasis. Bioorg Med Chem 2014, 22, 18-45, https://doi.org/10.1016/j.bmc.2013.11.048.

103.Et-Touys, A.; Fellah, H.; Sebti, F.; Mniouil, M.; Aneb, M.; Elboury, H.; Talbaoui, A.; Dakka, N.; Sadak, A.; Bakri, Y. In vitro antileishmanial activity of extracts from endemic Moroccan medicinal plant Salvia verbenaca (L.) Briq. ssp. verbenaca Maire (S. clandestina Batt. non L). European Journal of Medicinal Plants 2016, 16, 1-8, https://doi.org/10.9734/EJMP/2016/27891.

104.Osakabe, N.; Takano, H.; Sanbongi, C.; Yasuda, A.; Yanagisawa, R. Anti-inflammatory and anti-allergic effect of rosmarinic acid (RA); inhibition of seasonal allergic rhino conjunctivitis (SAR) and its mechanism. Biofactors 2004, 21, 127-131, https://doi.org/10.1002/biof.552210125.

105.Ruiz, P.; Haller, D. Functional diversity of flavonoids in the inhibition of the proinflammatory NF-kappa B, IRF, and Akt signaling pathways in murine intestinal epithelial cells. J Nutr 2006, 136, 664-671, https://doi.org/10.1093/jn/136.3.664.

106.Hmidani, A.; Bouhlali, E.d.T.; Ajebli, M.; Khouya, T.; Benlyas, M.; Alem, C. In vitro investigation of antioxidant and antihemolytic activities of three Lamiaceae species from Morocco. Beni-Suef Univ J Basic Appl Sci 2021, 10, 27, https://doi.org/10.1186/s43088-021-00116-9. 
107.Lahlou, S.; Israili, Z.H.; Lyoussi, B. Acute and chronic toxicity of a lyophilised aqueous extract of Tanacetum vulgare leaves in rodents. J Ethnopharmacol 2008, 117, 221-227, https://doi.org/10.1016/j.jep.2008.01.024.

108. Bellakhdar, J. La pharmacopée marocaine traditionnelle. Médecine arabe ancienne et savoirs populaires, $2^{\text {nd }}$ ed.; Ibis press, Paris, 1997.

109. Stroe, A.C.; Oancea, S. Immunostimulatory potential of natural compounds and extracts : A review. Curr Nutr Food Sci 2020, 16, 444-454.

110.Belmekki, N.; Bendimerad, N.; Seladji, M. Phytochemical constituents of some Algerian medicinal plants. $J$ Nat Prod Plant Resour 2012, 2, 558-562.

111.Jampílek J.; Král’ová K.; Fedor P. Bioactivity of Nanoformulated Synthetic and Natural Insecticides and Their Impact on Environment. In: Fraceto L.F.; S.S. de Castro V.L.; Grillo R.; Ávila D.; Caixeta Oliveira H.; Lima R. Eds. Nanopesticides 2020, Springer, Cham, https://doi.org/10.1007/978-3-030-44873-8_7.

112.Dwivedi, M. K.; Singh, P. K. Anti-Malarial Drug Resistance: Need for Novel Natural Products. In Advanced Pharmacological Uses of Medicinal Plants and Natural Products, 2020, 154-176, http://doi.org/10.4018/978-1-7998-2094-9.ch008.

113.Pavela, R. Larvicidal effects of various Euro-Asiatic plants against Culex quinquefasciatus Say larvae (Diptera: Culicidae). Parasitol Res 2008, 102, 555-559, https://doi.org/10.1007/s00436-007-0821-3.

114. Navarro L. Is the dichogamy of Salvia verbenaca (Lamiaceae) an effective barrier to self-fertilization? $P l$ Syst Evol 1997, 207, 111-117, https://doi.org/10.1007/BF00985212.

115. Navarro L. Effect of pollen limitation, additional nutrients, flower position and flowering phenology on fruit and seed production in Salvia verbenaca (Lamiaceae). Nord J Bot 1998, 18, 441-446.

116. Conceição Castro, M.; Roquete, C.; Gazarini, L. Above-ground phytomass and below-ground biomass production of Salvia verbenaca Linnée. Ecol Mediterr 2002, 28, 15-22, https://doi.org/10.3406/ecmed.2002.1570.

117.Bretzel, F.; Pezzarossa, B.; Benvenuti, S.; Bravi, A.; Malorgio, F. Soil influence on the performance of 26 native herbaceous plants suitable for sustainable Mediterranean landscaping. Acta Oecol 2009, 35, 657-663, https://doi.org/10.1016/j.actao.2009.06.008.

118.Fisher, R.L.; Florentine, S.K.; Westbooke, M.E. Arid land invasive weed Salvia verbenaca L. (wild sage): investigation into seedling emergence, soil seedbank, allelopathic effects, and germination. $20^{\text {th }}$ Australasian Weeds Conference, Perth, Western Australia, 11-15 September 2016.

119.Javaid, M.M.; Florentine, S.; Ali, H.H.; Weller, S. Effect of environmental factors on the germination and emergence of Salvia verbenaca L. cultivars (verbenaca and vernalis): An invasive species in semi-arid and arid rangeland regions. PLoS ONE 2018, 13, e0194319, https://doi.org/10.1371/journal.pone.0194319.

120.Naküboúlu, M. The Classification of the Salvia L. (Labiatae) species distributed in West anatolia according to phenolic compounds. Turk J Bot 2002, 26, 103-108.

121.Ifrim, C. Morphological peculiarities of the nutlets of some Salvia species (Lamiaceae). Contrib Bot 2012 , XLVII: 73-80.

122.Novo, L.A.B.; Covelo, E.F.; González, L. The Potential of Salvia verbenaca for phytoremediation of copper mine tailings amended with technosol and compost. Water Air Soil Pollut 2013, 224, 1513, https://doi.org/10.1007/s11270-013-1513-5.

123. Fatiha, R.A.; Kada, R.; Khelil, M.A.; Pujade-Villar, J. 2014. Biological control against the cowpea weevil (Callosobruchus chinensis L., Coleoptera: Bruchidae) using essential oils of some medicinal plants. J Plant Prot Res 2014, 54(3), https://doi.org/10.2478/jppr-2014-0032. 